\title{
Observations of the spectral dependence of linear particle depolarization ratio of aerosols using NASA Langley airborne High Spectral Resolution Lidar
}

\author{
S. P. Burton ${ }^{1}$, J. W. Hair ${ }^{1}$, M. Kahnert ${ }^{2,3}$, R. A. Ferrare ${ }^{1}$, C. A. Hostetler ${ }^{1}$, A. L. Cook $^{1}$, D. B. Harper ${ }^{1}$, T. A. Berkoff ${ }^{1}$, \\ S. T. Seaman ${ }^{1,4}$, J. E. Collins ${ }^{1,5}$, M. A. Fenn ${ }^{1,5}$, and R. R. Rogers ${ }^{1, a}$ \\ ${ }^{1}$ NASA Langley Research Center, MS 475, Hampton, VA 23681, USA \\ ${ }^{2}$ Research Department, Swedish Meteorological and Hydrological Institute, Folkborgsvägen 17, \\ 60176 Norrköping, Sweden \\ ${ }^{3}$ Department of Earth and Space Science, Chalmers University of Technology, 41296 Gothenburg, Sweden \\ ${ }^{4}$ National Institute of Aerospace, 100 Exploration Way, Hampton, VA 23666, USA \\ ${ }^{5}$ Science Systems and Applications, Inc., One Enterprise Pkwy, Hampton, VA 23666, USA \\ anow at: Lord Fairfax Community College, Middletown, VA 22645, USA
}

Correspondence to: S. P. Burton (sharon.p.burton@nasa.gov)

Received: 17 August 2015 - Published in Atmos. Chem. Phys. Discuss.: 11 September 2015

Revised: 16 November 2015 - Accepted: 17 November 2015 - Published: 7 December 2015

\begin{abstract}
Linear particle depolarization ratio is presented for three case studies from the NASA Langley airborne High Spectral Resolution Lidar-2 (HSRL-2). Particle depolarization ratio from lidar is an indicator of non-spherical particles and is sensitive to the fraction of non-spherical particles and their size. The HSRL-2 instrument measures depolarization at three wavelengths: 355, 532, and $1064 \mathrm{~nm}$. The three measurement cases presented here include two cases of dust-dominated aerosol and one case of smoke aerosol. These cases have partial analogs in earlier HSRL-1 depolarization measurements at 532 and $1064 \mathrm{~nm}$ and in literature, but the availability of three wavelengths gives additional insight into different scenarios for non-spherical particles in the atmosphere. A case of transported Saharan dust has a spectral dependence with a peak of 0.30 at $532 \mathrm{~nm}$ with smaller particle depolarization ratios of 0.27 and 0.25 at 1064 and $355 \mathrm{~nm}$, respectively. A case of aerosol containing locally generated wind-blown North American dust has a maximum of 0.38 at $1064 \mathrm{~nm}$, decreasing to 0.37 and 0.24 at 532 and $355 \mathrm{~nm}$, respectively. The cause of the maximum at $1064 \mathrm{~nm}$ is inferred to be very large particles that have not settled out of the dust layer. The smoke layer has the opposite spectral dependence, with the peak of 0.24 at $355 \mathrm{~nm}$, decreasing to 0.09 and 0.02 at 532 and $1064 \mathrm{~nm}$, respectively. The depolar-
\end{abstract}

ization in the smoke case may be explained by the presence of coated soot aggregates. We note that in these specific case studies, the linear particle depolarization ratio for smoke and dust-dominated aerosol are more similar at $355 \mathrm{~nm}$ than at $532 \mathrm{~nm}$, having possible implications for using the particle depolarization ratio at a single wavelength for aerosol typing.

\section{Introduction}

The impact of aerosols on climate depends on their horizontal and vertical distribution and microphysical properties. Lidar is an important tool for remote sensing of aerosol, because it provides vertically resolved information on aerosol abundance and aerosol type. One extremely useful lidar aerosol measurement is the linear particle depolarization ratio, an indicator of non-spherical particles. Polarization lidar is a large and active field, with recent contributions from ground-based networks, such as the European Aerosol Research Lidar Network (EARLINET; Pappalardo et al., 2014; Mamouri and Ansmann, 2014; Nisantzi et al., 2014) and the National Institute of Environmental Studies (NIES) East Asian network of lidars (Sugimoto et al., 2005; 
Nishizawa et al., 2011), and directed field campaigns, such as the Saharan Mineral Dust Experiment (SAMUM; Freudenthaler et al., 2009; Tesche et al., 2011) and the Saharan Aerosol Long-range Transport and Aerosol-Cloud Experiment (SALTRACE; Groß et al., 2015; Haarig et al., 2015); and others.

There is also considerable interest in global lidar observations from satellites. Global lidar observations of aerosol have been provided by the Cloud-Aerosol Lidar and Infrared Pathfinder Satellite Observations (CALIPSO) satellite since 2006 (Winker et al., 2007). Another satellite lidar, the experimental Cloud-Aerosol Transport System (CATS) instrument on the International Space Station (ISS) (McGill et al., 2012) was recently launched in January 2015, and the Earth Clouds Aerosols and Radiation Explorer (EarthCARE) satellite (Illingworth et al., 2015) is due to launch in 2018. CALIPSO linear particle depolarization ratio data have been used, for example, to assess the global distribution and transport of dust (e.g., Johnson et al., 2012; Liu et al., 2013; Yang et al., 2013). This measurement will also be part of the suite of measurements made by the ATLID (atmospheric lidar) on EarthCARE; however, CALIPSO measures depolarization at $532 \mathrm{~nm}$ and ATLID will measure it at $355 \mathrm{~nm}$ (Groß et al., 2014; Illingworth et al., 2015).

NASA Langley airborne High Spectral Resolution Lidars, HSRL-1 and HSRL-2, have participated in many processoriented field campaigns, have provided validation and calibration data for CALIPSO since 2006 (Rogers et al., 2011, 2014), and will also be useful for validating the EarthCARE lidar measurements. Since the airborne HSRL-2 measures the particle depolarization ratio at both the CALIPSO and EarthCARE wavelengths and also at $1064 \mathrm{~nm}$, observations from this instrument are useful for assessing how the measurements from the two satellite instruments will correspond. NASA's airborne HSRL-2 is the first HSRL system making depolarization measurements at three wavelengths. A ground-based Raman system operated by the Leibniz Institute of Tropospheric Research has also been recently upgraded to make three-wavelength depolarization measurements (Haarig et al., 2015).

Aerosol classification is one specific application of aerosol polarization measurements (Burton et al., 2012, 2013; Groß et al., 2013, 2014). The aerosol particle depolarization ratio from lidar is of key importance for the detection and assessment of dust and volcanic ash since it is a clear indicator of non-spherical particles. The particle depolarization ratio is also used to infer the amount of dust or ash in a mixture (Sugimoto and Lee, 2006; Tesche et al., 2009a, 2011; Ansmann et al., 2011, 2012; David et al., 2013; Burton et al., 2014; Mamouri and Ansmann, 2014). It is also sensitive to the size of the non-spherical particles (Ansmann et al., 2009; Sakai et al., 2010; Gasteiger et al., 2011; Gasteiger and Freudenthaler, 2014).

While a significant amount of study has been made of depolarization by dust and ash, smoke has also been observed to produce significant depolarization of lidar light in some cases (e.g., Fiebig et al., 2002; Sassen and Khvorostyanov, 2008; Sugimoto et al., 2010; Dahlkötter et al., 2014), but not in others (e.g., Müller et al., 2005). Even for cases with significant depolarization, the depolarization signature for smoke is generally smaller than for dust, at the wavelengths of 532 and $1064 \mathrm{~nm}$ where most lidar depolarization measurements of smoke have been made.

We will describe two dust-dominated cases and a smokedominated case where depolarizing aerosol was observed simultaneously at three wavelengths by the NASA Langley airborne HSRL-2 instrument. We show consistency between the three HSRL-2 cases and three previously published cases from the predecessor HSRL-1 instrument in which similar measurements were made at 532 and $1064 \mathrm{~nm}$, and we also discuss similarities and differences with published lidar measurements globally. We find that the three cases each have a different spectral dependence of the particle depolarization ratio. Accordingly, we discuss possible explanations for these differences with reference to published studies. We also point out implications for future space-based observations of aerosol depolarization. We begin in Sect. 2 with a description of the NASA Langley airborne HSRL instruments and the methodology for polarization measurements, including an assessment of systematic uncertainty. In Sect. 3 we describe and discuss the dust cases and in Sect. 4 we describe and discuss the smoke case. We summarize the discussion and conclude in Sect. 5. In the Appendix we give more details about the estimation of systematic uncertainty.

\section{Instrument description and measurement methodology}

The NASA Langley second-generation airborne HSRL-2 uses the HSRL technique (Shipley et al., 1983) to independently measure aerosol extinction and backscatter at 355 and $532 \mathrm{~nm}$ and the standard backscatter technique (Fernald, 1984) to measure aerosol backscatter at $1064 \mathrm{~nm}$. It also measures linear depolarization ratio at all three wavelengths. It is a follow-on to the successful airborne HSRL-1 instrument (Hair et al., 2008), which has made measurements at 532 and $1064 \mathrm{~nm}$ since 2006 (Rogers et al., 2009). For measurements at 532 and $1064 \mathrm{~nm}, \mathrm{HSRL}-2$ is essentially identical to HSRL-1. HSRL measurements of extinction and backscatter at $355 \mathrm{~nm}$ are made using an interferometer rather than an iodine filter. For $355 \mathrm{~nm}$ measurements of depolarization discussed here, the setup is very similar to the other channels; the small differences are explained in Sect. 2.1. Data are sampled at $0.5 \mathrm{~s}$ temporal and $30 \mathrm{~m}$ vertical resolutions. Aerosol backscatter and depolarization products are averaged $10 \mathrm{~s}$ horizontally $(\sim 1 \mathrm{~km}$ at nominal aircraft speed) and aerosol extinction products are averaged $60 \mathrm{~s}(\sim 6 \mathrm{~km})$ horizontally and $150 \mathrm{~m}$ vertically. Besides aerosol backscatter, extinction, and depolarization 
ratio, products also include horizontally and vertically resolved curtains of backscatter Ångström exponent and extinction Ångström exponent. Operational retrievals also provide mixing ratio of non-spherical-to-spherical backscatter (Sugimoto and Lee, 2006), aerosol type and partitioning of aerosol optical depth (AOD) by type (Burton et al., 2012), aerosol mixed-layer height (Scarino et al., 2014), and aerosol microphysics for spherical particles (Müller et al., 2014). HSRL-2 has been successfully deployed from the NASA LaRC King Air B200 aircraft on four field missions since 2012 and has obtained over 350 science flight hours. The typical flight altitude of the B200 during lidar operations is $9 \mathrm{~km}$. The data for the case studies presented here are available on the DISCOVER-AQ (Deriving Information on Surface Conditions from Column and Vertically Resolved Observations Relevant to Air Quality) data archive at http://www-air. larc.nasa.gov/missions/discover-aq/discover-aq.html or using the data doi:10.5067/Aircraft/DISCOVER-AQ/AerosolTraceGas.

\subsection{Depolarization optics}

In this paper, we will focus on the measurements of the linear particle depolarization ratio. Figure 1 shows a simplified diagram of the optics of the transmission system that are relevant to the measurement of depolarization. The primary optical components for the polarization of the transmitted beams are Glan laser polarizers, which have a very high polarization transmittance ratio of $2 \times 10^{5}: 1$ (i.e., the light is highly linearly polarized with an extremely small fraction of cross-polarized light). The calibration of depolarization for HSRL-2 is done in a manner similar to HSRL-1 (Hair et al., 2008) for all three wavelengths. The polarization axis of the outgoing light is matched to that of the receiver with an approach similar to that outlined by Alvarez et al. (2006) using seven fixed polarization angles between $\pm 45^{\circ}$, using the halfwave calibration wave plates indicated in Fig. 1. Following the alignment, the polarization gain ratio between the crosspolarized and co-polarized channels is routinely determined in flight by rotating the transmitted polarization $45^{\circ}$ relative to the receiver, so that both channels measure equal components of the co-polarized and cross-polarized backscatter returns, in a cloud-free portion of the profile; see Hair et al. (2008) for a detailed description of the calibrations and the caption accompanying Fig. 1 for more details of the HSRL-2 transmission optics.

The receiver optics relevant to depolarization measurements are shown in Fig. 2. The collimated light arrives from the telescope and is split into the three wavelengths using dichroic beam splitters. Each beam is then passed through an interference filter $(1064 \mathrm{~nm})$ or a combination of interference filter and etalon ( 355 and $532 \mathrm{~nm}$ ) to remove background scattering. The effective full-width half$\max (\mathrm{FWHM})$ bandwidths for the three channels are $0.4 \mathrm{~nm}$ $\left(3.5 \mathrm{~cm}^{-1}\right)$ at $1064 \mathrm{~nm}, 0.03 \mathrm{~nm}\left(1.1 \mathrm{~cm}^{-1}\right)$ at 532 , and

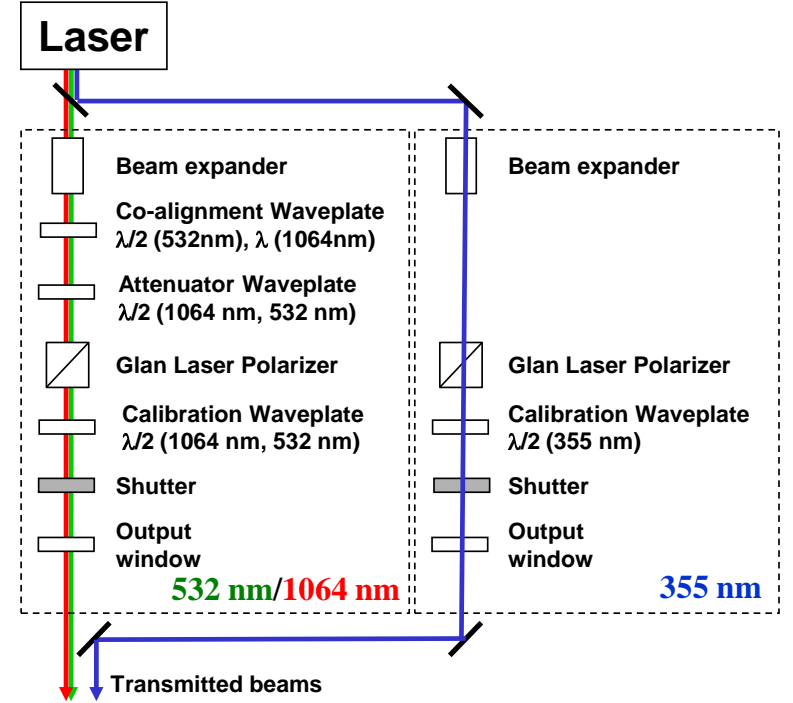

Figure 1. A simplified block diagram of the transmitter optics relevant for linear depolarization measurements by HSRL-2. The two Glan laser polarizers are the primary components ensuring the transmitted laser light is polarized. The motorized calibration wave plates are used to align the output polarization to the receiver polarization analyzers. The 532 and $1064 \mathrm{~nm}$ laser beams are maintained as a single beam. Since they do not exit the laser at the same polarization, a co-alignment wave plate is used to align the polarization from the two wavelengths so that the Glan laser polarizer does not significantly reduce the amount of light transmitted at one of the wavelengths. The attenuator wave plate is used to attenuate the $532 \mathrm{~nm}$ beam for eye safety considerations when flying at low altitudes, and for maximizing the power output otherwise.

$0.045 \mathrm{~nm}\left(3.6 \mathrm{~cm}^{-1}\right)$ at $355 \mathrm{~nm}$. Note that these bandwidths are narrow enough to completely exclude the rotational Raman sidebands from the receiver optics, which are found starting at $\pm 11.9 \mathrm{~cm}^{-1}$ for $\mathrm{N}_{2}$ and $\pm 14.4 \mathrm{~cm}^{-1}$ for $\mathrm{O}_{2}$ (Behrendt and Nakamura, 2002). The $1064 \mathrm{~nm}$ channel includes a half-wave plate, which can be used to correct any small polarization misalignment in the receiver system, since the 532 and $1064 \mathrm{~nm}$ beams are transmitted together. This half-wave plate is set during installation and is not rotated during normal operations. Next, each beam passes through polarization beam splitters (PBSs) to be separated into components that are co-polarized and cross-polarized with respect to the transmitted beam. Since the transmittance ratio of the light exiting a PBS is greater in the transmitted direction than in the reflected direction, a second cleanup PBS is included for each detector wavelength to further improve the transmittance ratio for the co-polarized light. The polarization transmittance ratio measured in the system is $300: 1$ for the cross-polarized light at $355 \mathrm{~nm}, 431: 1$ for the copolarized light at $355 \mathrm{~nm}$ (with two PBSs) and greater than 1000 : 1 for both polarization states at 532 and $1064 \mathrm{~nm}$. After exiting the polarization optics, the light in the $1064 \mathrm{~nm}$ channel goes directly to the avalanche photodetectors (APD). 


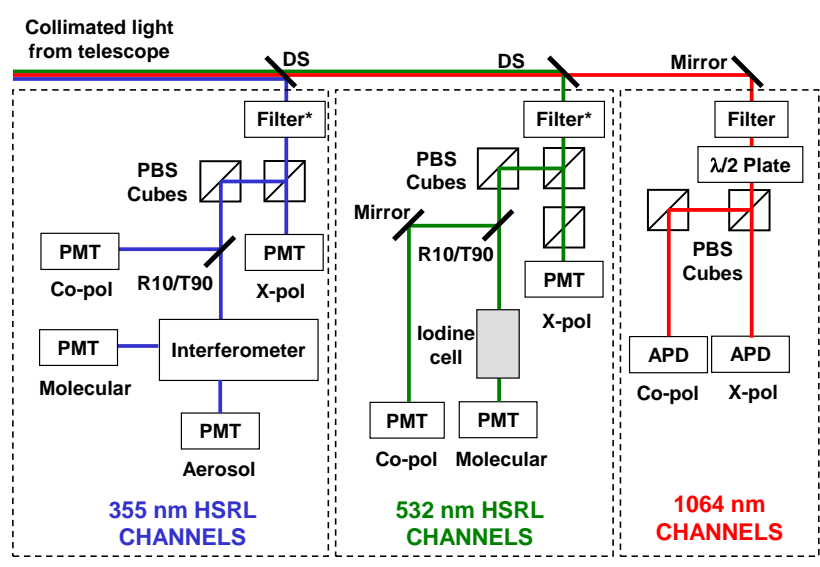

Figure 2. A simplified block diagram of the receiver optics relevant for linear depolarization measurements by HSRL-2. The abbreviations are as follows: PMT is photomultiplier tube; APD is silicon avalanche photodetector; DS is dichroic beam splitter; PBS is polarizing beam splitter; co-pol is co-polarized channel (with respect to the transmitted light); X-pol is cross-polarized channel. The collimated light arrives from the telescope and is split into the three wavelengths using dichroic beam splitters. The first optical component filters solar background using either an interference filter (indicated "Filter") or an interference filter and etalon in combination (indicated "Filter*"). The $1064 \mathrm{~nm}$ channel also includes an additional half-wave plate, which can be used to correct any small polarization misalignment in the receiver system since the 532 and $1064 \mathrm{~nm}$ beams are transmitted together. This half-wave plate is set during installation and is not rotated during normal operations. The light then passes through polarization beam splitters to be separated into components co-polarized and cross-polarized with respect to the transmitted beam. Since the transmittance ratio of the light exiting a PBS is greater in the transmitted direction than in the reflected direction, a second cleanup PBS is included for each detector wavelength to further improve the transmittance ratio for the co-polarized light. (An extra clean up PBS is also included for the cross-polarized light in the $532 \mathrm{~nm}$ channel.) The co-polarized signal and crosspolarized signal are used to determine volume depolarization ratio at each wavelength. The 355 and $532 \mathrm{~nm}$ co-polarized channels are split again and passed through additional optics to separate the aerosol and molecular signals (see text).

The co-polarized signal and cross-polarized signal are used to determine the volume depolarization ratio. As described by Hair et al. (2008) for HSRL-1, the co-polarized $532 \mathrm{~nm}$ channel is also split into a portion that is passed through an iodine cell leaving only molecular return and another portion that has both molecular and aerosol return. At $355 \mathrm{~nm}$, a portion of the co-polarized light is captured for the determination of the volume depolarization ratio, while the rest of the co-polarized light is transmitted through an interferometer to produce one channel that is dominated by the aerosol return with little signal from molecular scattering and a complementary channel that is dominated by the molecular signal with much less aerosol backscatter signal. The separation of the aerosol and molecular signals is the basis of the HSRL technique for extinction and backscatter retrieval. Since it also affects the systematic uncertainty in the particle depolarization ratio, it is included in the systematic uncertainty budget discussed in Sect. 2.2, below, and more details can be found in the Appendix.

The volume (or total) linear depolarization ratio is the ratio of the signal in the cross-polarized channel to that in the copolarized channel, normalized by the measured polarization gain ratio.

$\delta_{\mathrm{tot}}=G_{\mathrm{dep}} \frac{P^{\perp}}{P^{\|}}$

In Eq. (1), $P^{\perp}$ and $P^{\|}$are proportional to the light measured by the photodetectors or photomultipliers in the crosspolarized channel and the co-polarized channel, respectively; $G_{\text {dep }}$ is the electro-optical gain ratio between the two (for each wavelength) and $\delta^{\text {tot }}$ is the volume depolarization ratio, which is the ratio of the cross-polarized to co-polarized channel returns using the polarization gain ratio.

The particle depolarization ratio is calculated from the volume depolarization ratio using the following (Cairo et al., 1999):

$\delta_{\mathrm{a}}=\frac{R \delta_{\mathrm{tot}}\left(\delta_{\mathrm{m}}+1\right)-\delta_{\mathrm{m}}\left(\delta_{\mathrm{tot}}+1\right)}{R\left(\delta_{\mathrm{m}}+1\right)-\left(\delta_{\mathrm{tot}}+1\right)}$,

where $\delta_{\mathrm{a}}$ indicates the particle depolarization ratio, which will be used in all of the following discussions, $\delta_{\mathrm{m}}$ indicates the estimated molecular depolarization ratio, and $R$ indicates the total aerosol scattering ratio, which is the ratio of the aerosol plus molecular backscatter to the molecular backscatter, including both polarization components.

$R=\frac{\beta_{\mathrm{a}}+\beta_{\mathrm{m}}}{\beta_{\mathrm{m}}}$

\subsection{Systematic errors}

Systematic error can be a concern for polarization measurements. Potential sources of systematic error in volume depolarization ratio arise in the polarization optics and calibration. The retrieval of the particle depolarization ratio can potentially introduce additional systematic error related to the total aerosol scattering ratio or uncertainty in the molecular depolarization ratio value. We will provide an overview of the potential systematic errors here, including systematic uncertainty for volume depolarization ratio and propagated systematic uncertainty for the particle depolarization ratio. More details about these potential errors and the means of estimating the systematic uncertainty are given in the Appendix.

The linear volume depolarization ratio, given by Eq. (1), is the more basic measurement. Systematic errors in the volume depolarization ratio can arise from various sources, including calibration errors either in the polarization angle calibration or the polarization gain ratio calibration. A major concern for the measurement of depolarization is the potential for cross 
talk, which can arise from a number of sources, including imperfect polarization angle alignment, signal impurities due to imperfections in the polarization beam splitter (particularly the reflected channel), or other optics, including the aircraft window. Considering these sources, we estimate the systematic uncertainty in the volume depolarization ratio measurement to be the larger of $4.7 \%$ (relative) or 0.001 (absolute) in the $355 \mathrm{~nm}$ channel, the larger of $5 \%$ (relative) or 0.007 (absolute) in the $532 \mathrm{~nm}$ channel, and the larger of $2.6 \%$ (relative) or 0.007 (absolute) in the $1064 \mathrm{~nm}$ channel. Further discussion of these estimates is given in the Appendix.

As can be seen in Eq. (2), the particle depolarization ratio, $\delta_{\mathrm{a}}$, depends on the volume depolarization ratio, the molecular depolarization ratio, and the total aerosol scattering ratio. Therefore, an error in the assumed value of $\delta_{\text {mol }}$ or any systematic error in the total aerosol scattering ratio, $R$, can also cause systematic error in the particle depolarization ratio. Since the rotational Raman scattering sidebands are completely excluded from the receiver by the narrow-bandwidth background filters, the molecular depolarization arises only from the central Cabannes line and is very well characterized (She, 2001; Behrendt and Nakamura, 2002). More critically important is any potential systematic error in the total aerosol scattering ratio, $R$. We estimate the systematic uncertainty to be $4.1 \%$ in the $532 \mathrm{~nm}$ channel from an analysis of the stability of the aerosol-to-molecular gain ratio; $5 \%$ in the $355 \mathrm{~nm}$ channel including potential errors associated with gain ratio calibration transfer from the $532 \mathrm{~nm}$ channel; and $20 \%$ in the $1064 \mathrm{~nm}$ channel taking into account the retrieval of backscatter using an estimated lidar ratio. Again, further discussion can be found in the Appendix.

The estimates given above are intended to be conservative estimates of the systematic uncertainty confidence limit, such that we expect a high probability that the systematic error is less than this value. The systematic uncertainties on the three quantities, $\delta_{\mathrm{mol}}, \delta_{\mathrm{tot}}$, and $R$, are combined in quadrature using standard propagation of errors for independent variables, as described in the Appendix. The propagated systematic uncertainties for the case studies are included in the figures and tables in Sects. 3 and 4.

\section{Dust}

In this section we discuss two case studies in which HSRL-2 made three-wavelength measurements of the depolarization of dust.

\subsection{Case study: 13 July 2014, dust in the residual layer in the Midwest US}

On 13 July 2014, HSRL-2 aboard the B200 made measurements at three wavelengths on a transit flight from Virginia to Colorado for the DISCOVER-AQ field mission (http://discover-aq.larc.nasa.gov/). The aerosol backscatter at three wavelengths and aerosol extinction at two wavelengths are shown in Fig. 3 for a $180 \mathrm{~km}$ portion of the flight track in Missouri and Kansas, in the midwestern United States. Several aerosol layers are evident. For this case study, we will focus on a dust-dominated layer that extends from just above the boundary layer to about $3200 \mathrm{~m}$ a.s.l. Back trajectories derived from the NOAA Hybrid Single Particle Lagrangian Integrated Trajectory Model (HYSPLIT) tool (ready.arl.noaa.gov) indicate that this layer probably has a Saharan origin and has undergone a very long transport period of about 14 days. Non-spherical particles, such as dust, have a distinct signature in lidar particle depolarization measurements. The linear particle depolarization ratio measurement curtains for all three wavelengths are shown in Fig. 4. Peak values of the particle depolarization ratio in the $1600-2300 \mathrm{~m}$ altitude range are approximately $0.246 \pm 0.018$ (standard deviation for the sample $) \pm(0.055$ systematic $), 0.304 \pm 0.005 \pm(0.022)$, and $0.270 \pm 0.005 \pm(0.009)$ at 355,532 , and $1064 \mathrm{~nm}$, respectively. These high values of the particle depolarization ratio indicate that the layer is dominated by dust (approximately $90 \%$ dust using the methodology of Sugimoto and Lee (2006)). Note that the particle depolarization ratio at $532 \mathrm{~nm}$ for this layer is larger than at either 355 or $1064 \mathrm{~nm}$. The $532 \mathrm{~nm}$ layer optical depth is approximately 0.1 and the total aerosol scattering ratio at $532 \mathrm{~nm}$ is 2.3 . The backscatter Ångström exponent $(532 / 1064 \mathrm{~nm}$ ) is $0.45 \pm 0.03$ (standard deviation) for this layer. Table 1 includes these values for this sample and for the other cases discussed here. Values for the particle depolarization ratios and backscatter Ångström exponents are within the interquartile range we previously reported for dust-dominated aerosol measurements from HSRL-1 (Burton et al., 2013).

Figure 5 shows both the particle depolarization ratio and volume depolarization ratio measurements for all altitudes at 17:12 UT (17.2 UT). The particle depolarization ratio random and systematic uncertainties are also shown.

The predecessor of the HSRL-2, the NASA Langley HSRL-1 instrument, observed several cases of transported Saharan dust in the Caribbean in August 2010, for example the case on 18 August 2010 that is shown by Burton et al. (2012). For that case, the particle depolarization ratios at 532 and $1064 \mathrm{~nm}$ are $0.33 \pm 0.02$ (standard deviation) and $0.28 \pm 0.01$, slightly higher than the 13 July 2014 case but agreeing within the spread of the measurement sample. The backscatter Ångström exponent $(532 / 1064 \mathrm{~nm})$ is $0.68 \pm 0.13$ (Table 1). As on 13 July 2014, the particle depolarization ratios and the backscatter Ångström exponent are within the interquartile range of values for dust-dominated aerosol reported for HSRL-1. The backscatter Ångström exponents $(532 / 1064 \mathrm{~nm})$ are larger than the value reported for pure Saharan aerosol in Morocco (Tesche et al., 2009b), which is $0.28 \pm 0.16$. The larger values may be consistent with large particle loss during transport, discussed in more detail below. 

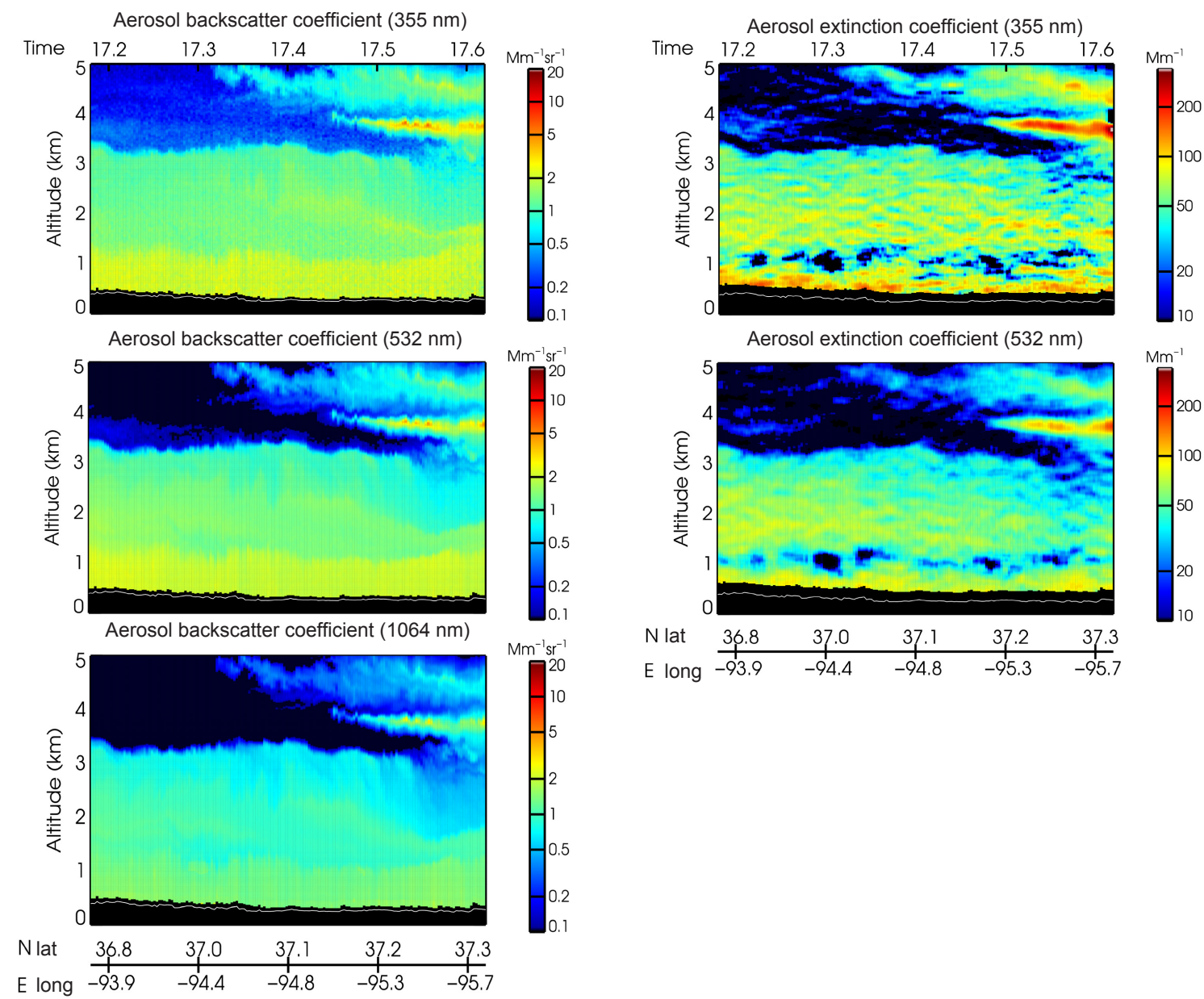

Figure 3. Curtains of aerosol backscatter and extinction coefficients from HSRL-2 for observations on 13 July 2014 for a flight segment in Missouri and Kansas in the midwestern United States.

Table 1. Measured properties for specific dust and smoke samples. To obtain these values, samples were taken at specific times and altitudes comprising 400-4500 distinct measurement points. For the dust cases, values were chosen near the peak value of the $532 \mathrm{~nm}$ particle depolarization ratio, where it can be inferred that the aerosol is nearly pure dust. The values are reported as mean \pm standard deviation for the sample. Systematic uncertainties for the particle depolarization ratio from HSRL-2 are indicated in parentheses.

\begin{tabular}{|c|c|c|c|c|c|c|}
\hline & & $\begin{array}{r}\text { Layer } \\
\text { AOD } \\
(532 \mathrm{~nm})\end{array}$ & $\begin{array}{r}\text { Linear particle } \\
\text { depolarization } \\
\text { ratio }(1064 \mathrm{~nm})\end{array}$ & $\begin{array}{l}\text { Linear particle } \\
\text { depolarization } \\
\text { ratio }(532 \mathrm{~nm})\end{array}$ & $\begin{array}{r}\text { Linear particle } \\
\text { depolarization } \\
\text { ratio (HSRL-2 only) } \\
(355 \mathrm{~nm})\end{array}$ & $\begin{array}{r}\text { Aerosol backscatter } \\
\text { Ångström } \\
\text { exponent } \\
(532 / 1064)\end{array}$ \\
\hline $\begin{array}{l}\text { Midwest US } \\
13 \text { July } 2014\end{array}$ & transported Saharan dust & 0.10 & $0.270 \pm 0.005(0.009)$ & $0.304 \pm 0.005(0.022)$ & $0.246 \pm 0.018(0.055)$ & $0.46 \pm 0.03$ \\
\hline $\begin{array}{l}\text { Caribbean } \\
18 \text { August } 2010\end{array}$ & transported Saharan dust & 0.25 & $0.278 \pm 0.012$ & $0.327 \pm 0.018$ & - & $0.68 \pm 0.13$ \\
\hline $\begin{array}{l}\text { Chihuahuan Desert } \\
8 \text { February } 2013\end{array}$ & local North American dust & 0.02 & $0.383 \pm 0.006(0.011)$ & $0.373 \pm 0.014(0.023)$ & $0.243 \pm 0.046(0.045)$ & $-0.09 \pm 0.04$ \\
\hline $\begin{array}{l}\text { Pico de Orizaba } \\
12 \text { March } 2006\end{array}$ & local North American dust & 0.31 & $0.400 \pm 0.009$ & $0.334 \pm 0.018$ & - & $-0.9 \pm 0.4$ \\
\hline $\begin{array}{l}\text { Denver } \\
17 \text { July } 2014\end{array}$ & smoke & 0.05 & $0.018 \pm 0.002(0.008)$ & $0.093 \pm 0.015(0.012)$ & $0.240 \pm 0.010(0.021)$ & $1.1 \pm 0.1$ \\
\hline $\begin{array}{l}\text { East Coast US } \\
2 \text { August } 2007\end{array}$ & smoke & 0.06 & $0.019 \pm 0.005$ & $0.068 \pm 0.010$ & - & $0.62 \pm 0.25$ \\
\hline
\end{tabular}




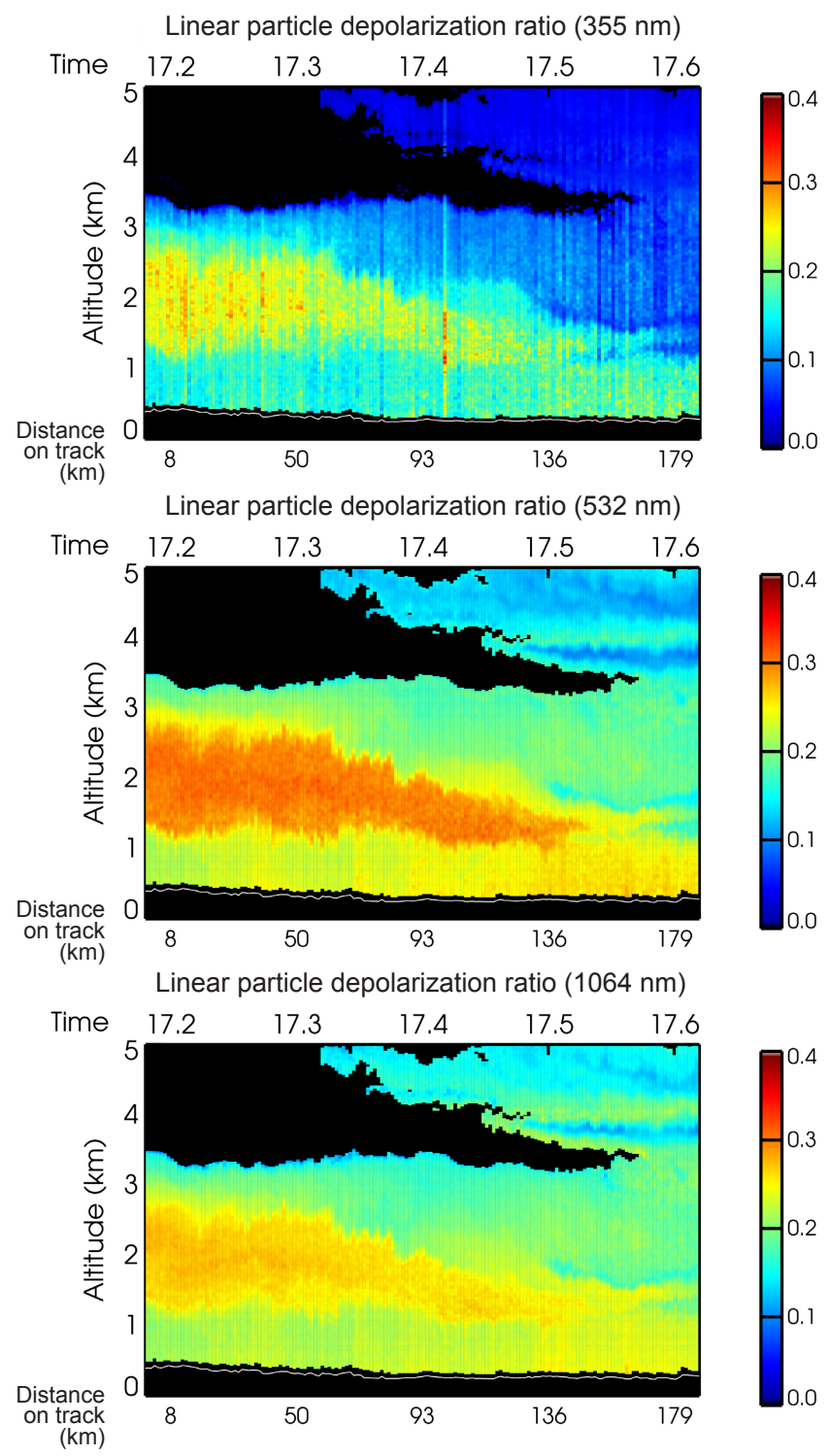

Figure 4. The linear particle depolarization ratio at three wavelengths measured by the HSRL-2 for the same flight segment shown in Fig. 3.

The spectral dependence of the particle depolarization ratio can also be compared to measurements of the Saharan dust particle depolarization ratio reported by Freudenthaler et al. (2009) for the SAMUM I campaign. For the four dates presented in their Fig. 7, the minimum and maximum values for $355 \mathrm{~nm}$ from the portable lidar system (POLIS) were $0.21-0.31$ (compare 0.25 for NASA HSRL-2 case); at $532 \mathrm{~nm}$ they were $0.29-0.33$ from the German Aerospace Center (DLR) HSRL (compare 0.30 and 0.33 from NASA HSRL-2 and HSRL-1) and at $1064 \mathrm{~nm}$ they were 0.22-0.29 from the DLR HSRL (compare 0.27 and 0.28 from NASA HSRL-2 and HSRL-1). Again, the reported values at $532 \mathrm{~nm}$ exceed those at the other wavelengths. Indeed all three of these case studies, Saharan dust close to the source (Freudenthaler et al., 2009), transported Saharan dust observed in the Caribbean by HSRL-1, and transported Saharan dust observed by HSRL-2 in the midwestern US, have similar wavelength dependence of the particle depolarization ratio.

\subsection{Case study: 8 February 2013, dust in the Southwest US}

A less typical observation of dust-dominated aerosol was made by the HSRL-2 instrument on 8 February 2013. On a transit flight to Virginia at the conclusion of the DISCOVERAQ California field campaign, HSRL-2 aboard the B200 made three-wavelength measurements of a locally produced dust layer very close to the source in the US Southwest. Figure 6 shows the lidar curtain of the aerosol backscatter coefficient at $532 \mathrm{~nm}$ for a segment of approximately $280 \mathrm{~km}$ in Arizona and New Mexico. The highest backscatter values are near the surface and are associated with the dust layer. More tenuous layers are also visible between 3 and $5 \mathrm{~km}$, which are probably smoke. The discussion will focus primarily on the dust layer for this example. Figure 7 shows the particle depolarization ratio at three wavelengths for the same flight segment.

The maximum backscatter values occur within $400 \mathrm{~m}$ of the ground at about 17:08 UT (17.14 UT), near the Potrillo volcanic fields in New Mexico in the Chihuahuan Desert. The layer is shallower than the previous case, and the layer AOD is only about 0.02 at $532 \mathrm{~nm}$, but it is very strongly scattering, with a $532 \mathrm{~nm}$ total aerosol scattering ratio of 3.1. The peak particle depolarization ratio is $0.24 \pm 0.05 \pm(0.05)$, $0.37 \pm 0.01 \pm(0.02)$, and $0.383 \pm 0.006 \pm(0.011)$ at 355 , 532 , and $1064 \mathrm{~nm}$, respectively (the first uncertainty value represents standard deviation and the parentheses indicate systematic uncertainty). Given that these very large depolarization ratio values occur very close to the ground, we infer that this observation is close to the source region. This observed dust layer is a locally generated, wind-driven aerosol from a bare soil surface in desert scrubland. The large particle depolarization ratios provide confidence that this air mass is dominated by dust aerosol rather than a mixture from distinct sources. The backscatter Ångström exponent $(532 / 1064 \mathrm{~nm})$ is $-0.09 \pm 0.04$.

Figure 8 shows line plots of the volume depolarization ratio and the particle depolarization ratio profiles, plus error bars. The systematic uncertainties are generally larger at $355 \mathrm{~nm}$. This error magnification at $355 \mathrm{~nm}$ occurs in both dust-dominated cases because of the spectral dependence of the scattering and consequent small total aerosol scattering ratio at $355 \mathrm{~nm}(R=1.2$ at $355 \mathrm{~nm})$. However, the systematic uncertainties are small enough to clearly reveal that the wavelength dependence of the particle depolarization ratio is quite different from the Saharan dust cases discussed previously, both those measured by the NASA Langley HSRL-1 and HSRL-2 instruments and by other researchers. In our 

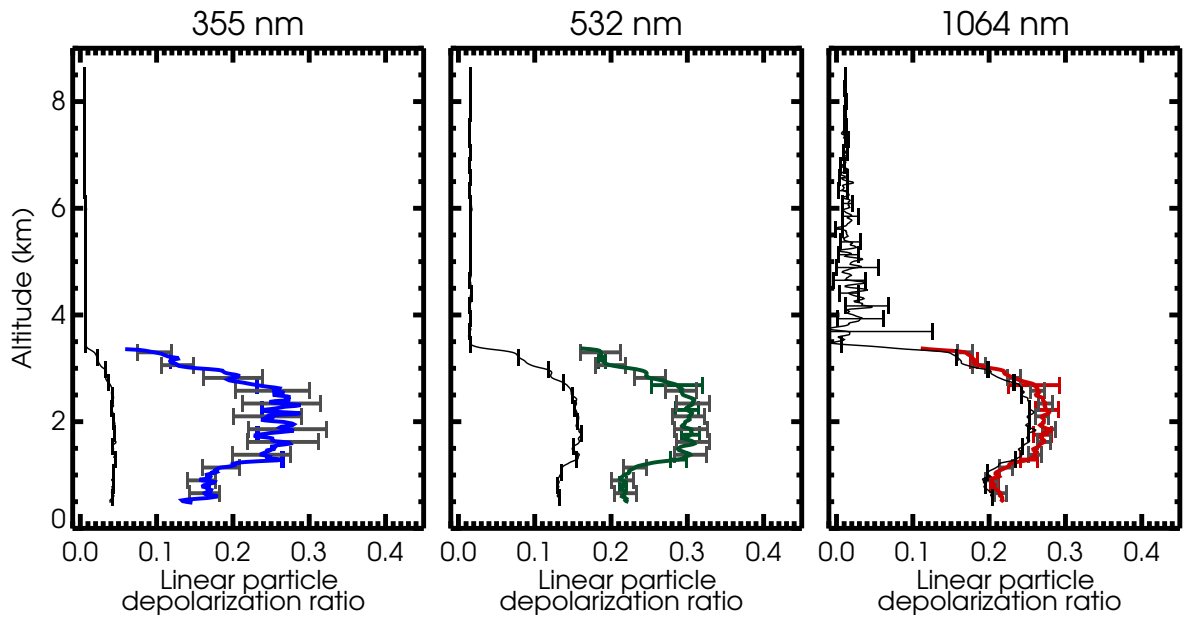

Figure 5. Line plots illustrating the volume and linear particle depolarization ratio profile for the HSRL-2 measurements at 17:12 UT (17.2 UT) on 13 July 2014. The volume depolarization ratio is shown as a thin black line. The error bars on the volume depolarization ratio represent random error (most are small and mostly obscured except $1064 \mathrm{~nm}$ ). The particle depolarization ratio is shown as a thick colored line. Colored error bars indicate random error (most are small enough to be obscured by the line) while gray error bars indicate systematic uncertainty, estimated as described in the text. Systematic uncertainty is not shown for the volume depolarization ratio; see text for estimate. The vertical resolution of these measurements is $30 \mathrm{~m}$ and the horizontal resolution is $10 \mathrm{~s}$ for all wavelengths.

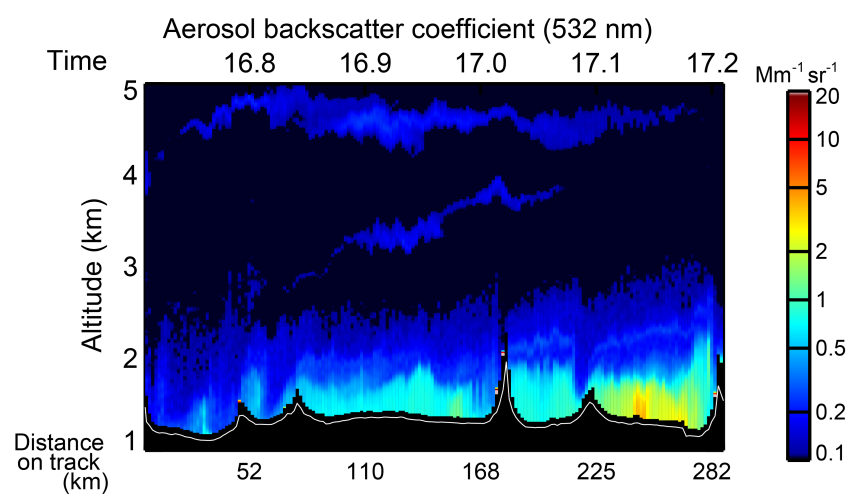

Figure 6. Measurement curtain of aerosol backscatter coefficient at $532 \mathrm{~nm}$ from the HSRL-2 instrument for a $280 \mathrm{~km}$ flight segment over the southwestern US on 8 February 2013, showing locally generated dust in approximately the first kilometer above the surface, as well as very tenuous smoke plumes at higher altitude. This flight segment was part of a transit flight from a field mission in California back to the B200 home base in Virginia. The selected flight segment is approximately $280 \mathrm{~km}$ and begins (at the left margin) on the slopes of the Dos Cabezas Mountains of Arizona and ends (at the right margin) at the Franklin Mountains in New Mexico. The ground surface is marked with a white line.

observations of transported Saharan aerosol, including the case discussed in Sect. 3.1, the particle depolarization ratio at $532 \mathrm{~nm}$ exceeds the value at $1064 \mathrm{~nm}$, but this case differs in that the $1064 \mathrm{~nm}$ particle depolarization ratio slightly exceeds the $532 \mathrm{~nm}$ value. The difference is primarily in the $1064 \mathrm{~nm}$ value, since the 355 and $532 \mathrm{~nm}$ particle depolarization ratios are similar to the Saharan aerosol cases.
However, there was a previous observation by HSRL-1 of windblown North American dust on the slope of the Pico de Orizaba near Veracruz, Mexico, on 12 March 2006 (Burton et al., 2014; de Foy et al., 2011), which provides an analogous case for comparison. In this case the particle depolarization ratios are $0.33 \pm 0.02$ (standard deviation) and $0.40 \pm 0.01$ at 532 and $1064 \mathrm{~nm}$, respectively, similar to the Chihuahuan Desert aerosol on 8 February 2013, and the backscatter Ångström exponent $(532 / 1064 \mathrm{~nm})$ is $-0.9 \pm 0.4$. Note that these backscatter Ångström exponents are significantly smaller than the transported Saharan dustdominated aerosol cases discussed in Sect. 3.1.

\subsection{Discussion of spectral dependence of the particle depolarization ratio of dust-dominated aerosol}

Figure 9 shows the linear particle depolarization ratio at all three wavelengths for the four HSRL-1 and HSRL-2 cases discussed so far. The HSRL-2 observations of transported Saharan aerosol have spectral dependence consistent with the elevated Saharan dust-dominated aerosol reported by Freudenthaler et al. (2009) for the DLR airborne HSRL and ground-based lidar. However, the NASA HSRL-1 and HSRL-2 observations of North American dust at low altitude close to the source appear to fall into a different category. Although all of the observations discussed here from the NASA HSRL-2 and those of Saharan desert aerosol in Africa (Freudenthaler et al., 2009) have particle depolarization ratios at $355 \mathrm{~nm}$ that are less than those at $532 \mathrm{~nm}$, there is a large difference at the longest wavelength, with larger $1064 \mathrm{~nm}$ particle depolarization ratios for the local dust-dominated cases. 


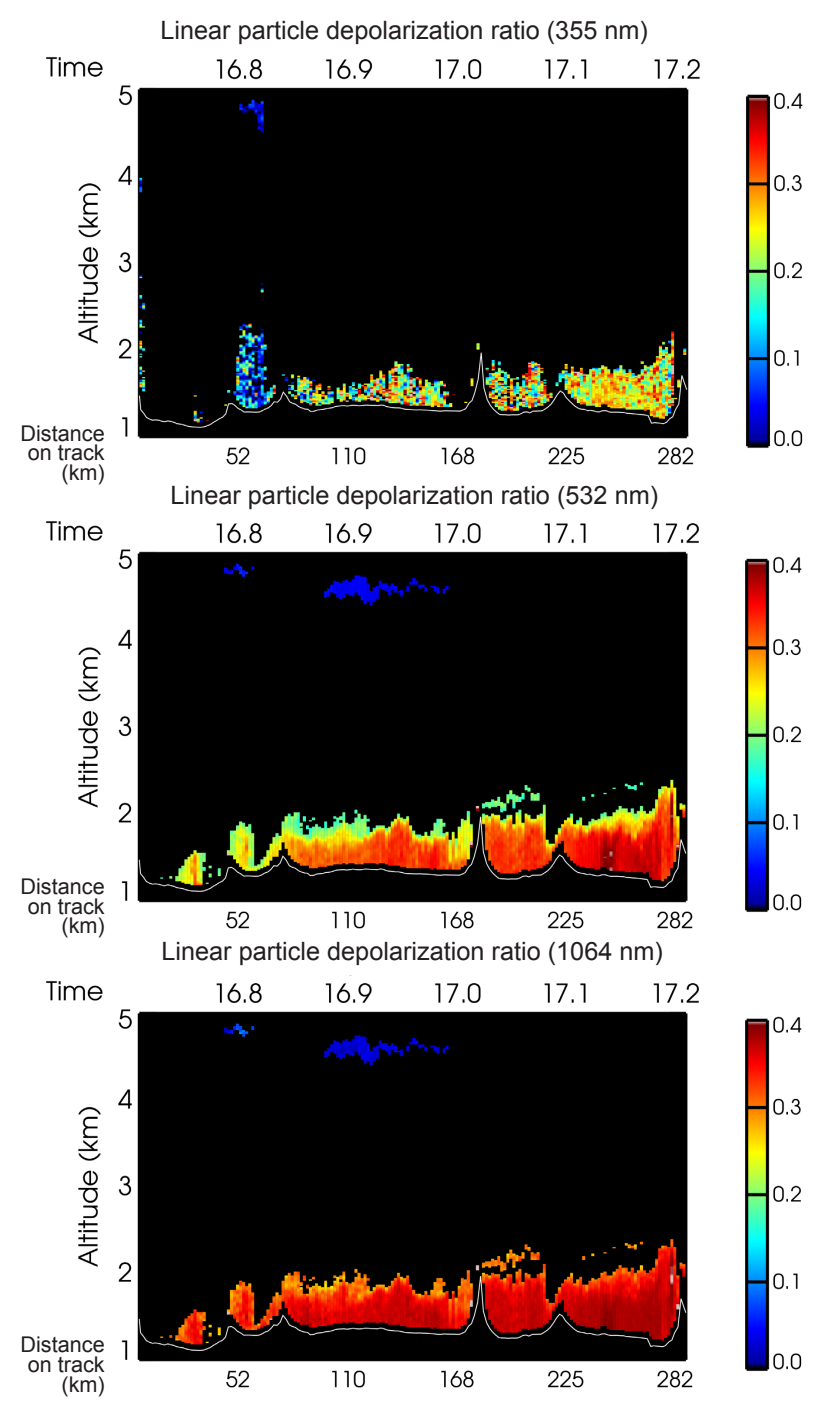

Figure 7. The linear particle depolarization ratio at three wavelengths observed by HSRL-2 on 8 February 2013 in the southwestern US for the flight segment shown in Fig. 6.

Furthermore, the backscatter Ångström exponents in the Chihuahuan Desert observation on 8 February 2013 and on Pico de Orizaba on 12 March 2006 are much smaller compared to $0.45-0.68$ for the cases of transported Saharan dust. These smaller values are an indication of larger particle sizes (Sasano and Browell, 1989) (although it must be noted that the backscatter Ångström exponent is also sensitive to other factors besides particle size, such as relative humidity (Su et al., 2008)). Maring et al. (2003) shows measured size distributions for dust layers over the Canary Islands and Puerto Rico at different stages of transport, and concluded by modeling of these distributions that a combination of Stokes gravitational settling and an offset upward velocity would explain these observations. According to that model, the volume mean diameter decreases only $20 \%$ after 10 days of atmospheric transport, but $80 \%$ of that change occurs within the first 2 days. In other words, the size distributions for transported dust-dominated aerosol are similar whether transported long distances or short distances, but even layers transported short distances probably have already lost the largest particles to settling. This model applies to Saharan dust transport, but it raises the possibility that dust-dominated aerosol size distributions immediately over the source, such as the North American dust cases presented here, will have some proportion of particles significantly larger than those found in the transported layers.

The spectral dependence of the particle depolarization ratio is known to be related to the size of the non-spherical particles (Mishchenko and Sassen, 1998). We infer that the difference in depolarization spectral dependence, and in particular the $1064 \mathrm{~nm}$ values, are due to larger particles in the observations of windblown dust close to the surface. Groundbased lidar observations by Ansmann et al. (2009) of convective plumes of dust and sand being lifted from the surface in Morocco included extremely large particle depolarization ratios of $0.50-1.0$ at $710 \mathrm{~nm}$. This supports the connection between large particle depolarization ratios at the longer wavelengths and large particles sizes. However, the long-wavelength values in the current case study are not nearly as extreme, suggesting perhaps that the particle sizes are not as large.

Theoretical calculations to date have shown that it is difficult to quantitatively predict the spectral dependence of the particle depolarization ratio for dust (Gasteiger et al., 2011; Wiegner et al., 2009; Gasteiger and Freudenthaler, 2014), due in part to the need for parameterizing the shape of the dust aerosols as spheroids or other simplified shapes.

In a theoretical treatment of a particular measurement case, Gasteiger et al. (2011) modeled the particle depolarization ratio at multiple wavelengths using size distributions and refractive indices appropriate for SAMUM measurements, using mixtures of various irregular shapes to represent the dust particles. For their reference distribution, the modeled particle depolarization ratio reflects a spectral dependence with a peak in the middle of the wavelength range. Calculated values at $355,532,710$, and $1064 \mathrm{~nm}$ were 0.275 , $0.306,0.311,0.298$, respectively, consistent with the measurements we report for the Saharan dust-dominated cases from the NASA HSRL-1 and HSRL-2. However, for the dust-dominated cases in the immediate vicinity of North American sources, the measured maximum shifts to longer wavelengths, and there is no longer agreement with the modeled values at $1064 \mathrm{~nm}$.

Gasteiger et al. (2011) do not show results for size distributions with different size particles, but Gasteiger and Freudenthaler (2014) perform theoretical calculations using spheroids for various size parameters (single particles). These calculations show that the first peak in the spectral depolarization ratio shifts to larger wavelengths as particle size increases. This result, based on highly simplified modeling of dust aerosol, should be used only cautiously, but in general 

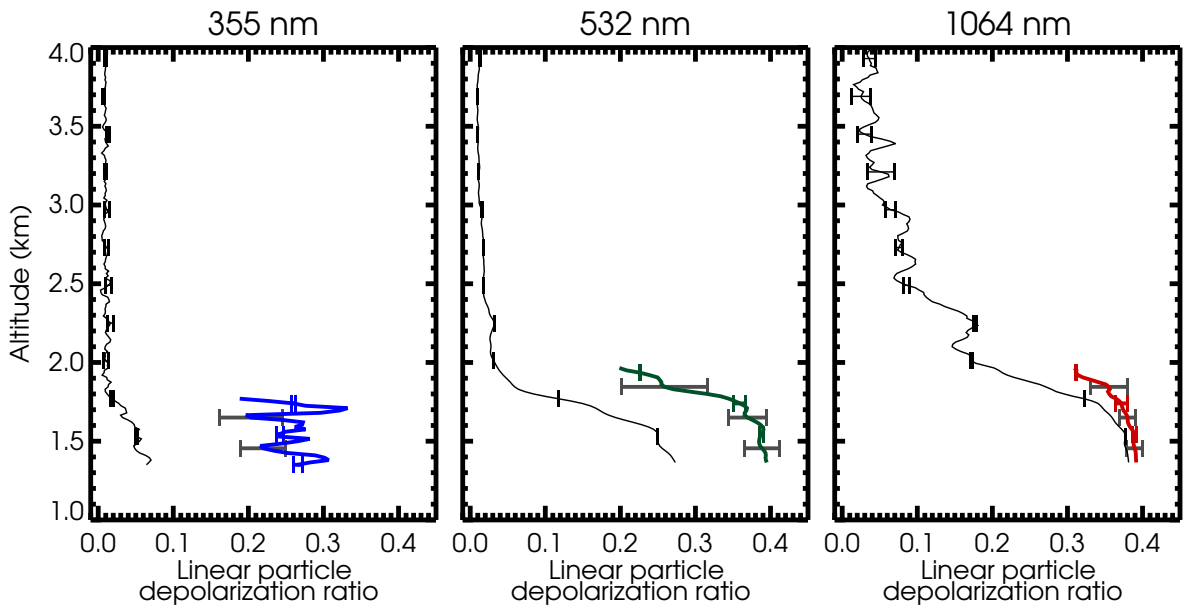

Figure 8. Line plots illustrating the volume and linear particle depolarization ratio profile for the HSRL-2 measurements at 17:08 UT (17.14 UT) on 8 Feb 2013. Error bars and resolutions as described for Fig. 5.

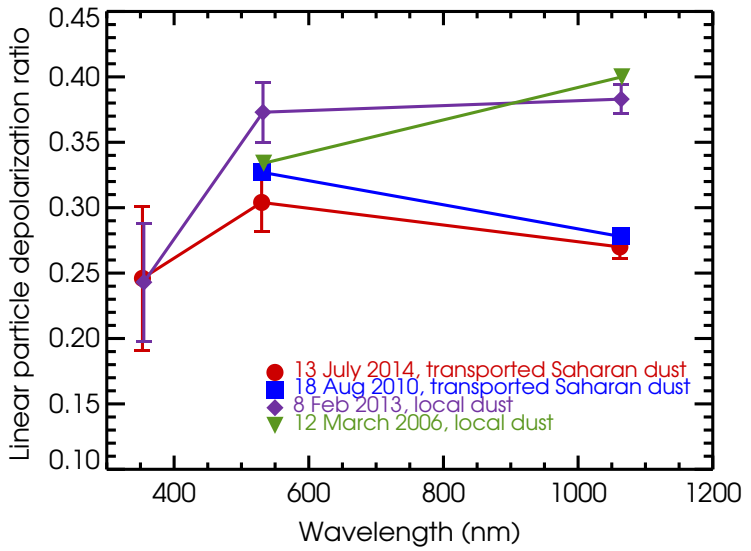

Figure 9. The linear particle depolarization ratio measured by HSRL-2 and HSRL-1 for the four dust cases discussed in the text. Note the spectral dependence (and in particular the $1064 \mathrm{~nm}$ channel) is different for the two local dust-dominated aerosol cases compared to the transported Saharan dust-dominated aerosol cases.

supports the notion that the spectral particle depolarization ratio is sensitive to particle size.

\section{Smoke}

\subsection{Case study: 17 July 2014 North American wildfire smoke}

Our third three-wavelength case study is an observation of a smoke plume with large particle depolarization ratios measured during the Colorado deployment of the DISCOVERAQ field mission on 17 July 2014 at about $8 \mathrm{~km}$ altitude. At this time, wildfire smoke from fires in the Pacific Northwest of the United States blanketed much of the region, visible in a composited Moderate Resolution Imaging Spectroradiometer (MODIS) true color image in Fig. 10. (The smoke situation on that day is also discussed in University of Maryland Baltimore County's US Air Quality Smog Blog; see http://alg.umbc.edu/usaq/archives/2014_07.html). Figure 11 shows a view of the smoke plume from the B200.

Figures 12 and 13 show HSRL-2 measurements of $532 \mathrm{~nm}$ backscatter and three-wavelength linear particle depolarization ratios as time-height curtains and Fig. 14 illustrates a profile at 19:18 UT (19.3 UT) as a line plot with random and systematic uncertainty error bars. The pictured flight segment began near the Boulder Atmospheric Observatory tall tower north of downtown Denver and proceeded south for about $70 \mathrm{~km}$ to Chatfield State Park, then turned north again on a parallel track for $135 \mathrm{~km}$ to Fort Collins. The layer optical thickness is about 0.05 at $532 \mathrm{~nm}$ and the total aerosol scattering ratio is 2.9. This layer was at high altitude near the aircraft, in the overlap region, where there is a range dependence of the detected backscattered light (Hair et al., 2008). While backscattered light from a distant target is fully imaged in the detector, light from a near-field target is focused beyond the field stop, resulting in overfilling of the field stop at small range from the lidar. This loss of signal is range dependent and prevents the retrieval of aerosol extinction. For this reason, the layer optical depth given above is an estimate using the backscatter measurements and an assumed lidar ratio of $70 \mathrm{sr}$, which is typical for smoke. Volume depolarization ratio measurements and total aerosol scattering ratio measurements are ratios of two channels that are equally affected and therefore have no range-dependent overlap function. For this layer, the particle depolarization ratio is greatest at $355 \mathrm{~nm}$, about $0.24 \pm 0.01 \pm(0.02)$ at the southern end of the flight track, and about $0.17-0.22$ in the more northern portions. The particle depolarization ratio at $532 \mathrm{~nm}$ is as large as $0.09 \pm 0.02 \pm(0.01)$ at the southern 


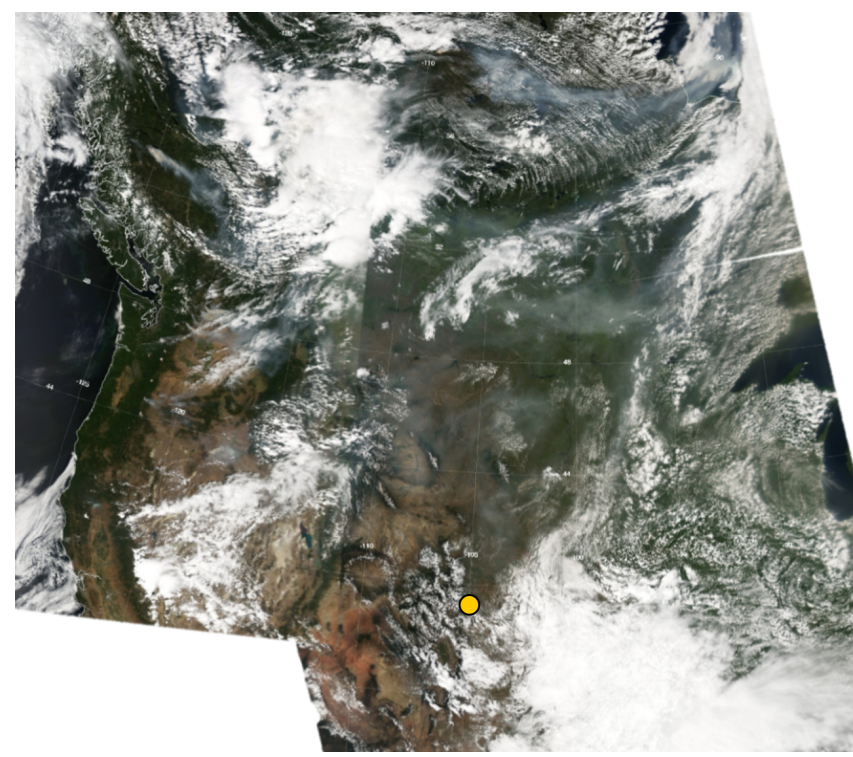

Figure 10. MODIS Aqua true color images of much of North America on 17 July 2014, composited from four granules at 19:45, 19:50, 21:25, and 21:30 UT. The approximate location of the HSRL-2 observations discussed in the text (Denver, Colorado) is marked with a yellow dot. The bright white is clouds and snow cover and the gray is smoke. Several distinct smoke plumes indicate sources in the US Pacific Northwest and in western Canada within the cloud-free area on the western part of the continent. Significant smoke layers from these fires blanket the mid-continent cloud-free areas in the northern portion of the image. The HSRL-2 measurements are close to the southern edge of the extensive smoke field.

end of the flight track and down to about 0.06 at the northern end. The particle depolarization ratio at $1064 \mathrm{~nm}$ is about $0.018 \pm 0.002 \pm(0.008)$ throughout the region (parenthesis indicate systematic uncertainties). Note that the wavelength dependence of the particle depolarization ratio is opposite to what was observed for dust on 8 February 2013, in that the smoke plume has a significantly larger particle depolarization ratio at the shorter wavelengths. Since this smoke layer has a very high total aerosol scattering ratio, the systematic uncertainties are relatively small, and it is clear even at the upper limit of the systematic uncertainty that the $355 \mathrm{~nm}$ particle depolarization ratio significantly exceeds the $532 \mathrm{~nm}$ value and the $532 \mathrm{~nm}$ value significantly exceeds the $1064 \mathrm{~nm}$ value.

The pattern of larger particle depolarization ratios at $532 \mathrm{~nm}$ compared to $1064 \mathrm{~nm}$ has regularly been observed for smoke with the HSRL-1 instrument; indeed the HSRL-1 aerosol classification methodology (Burton et al., 2012) takes advantage of this spectral dependence. One such example is the aged southwest Canadian smoke plume observed on the eastern seaboard of the US on 2 August 2007 that was shown by Burton et al. (2012). For that prior case, the particle depolarization ratios were $0.07 \pm 0.01$ and $0.019 \pm 0.005$ at 532 and $1064 \mathrm{~nm}$, respectively.

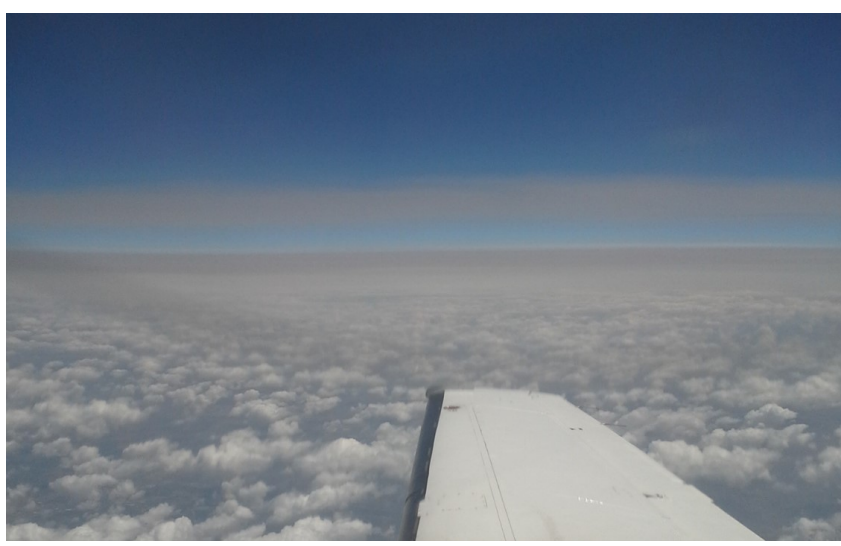

Figure 11. View of the smoke plume aloft on 17 July 2013 taken from the B200. Photo credit: Tim Berkoff.

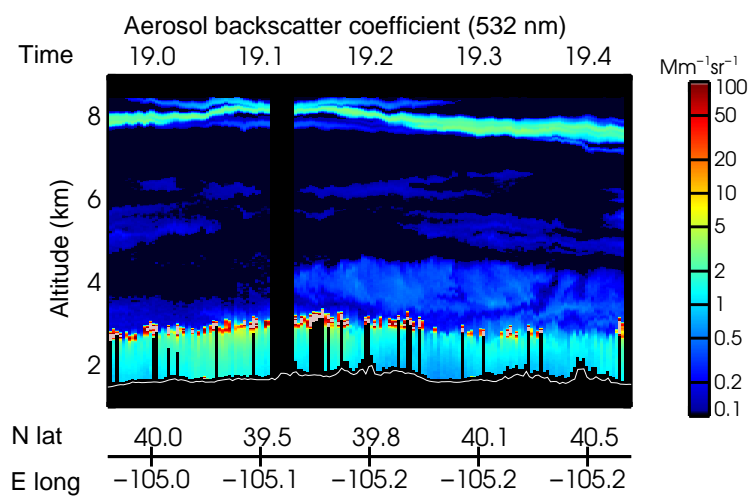

Figure 12. $532 \mathrm{~nm}$ aerosol backscatter coefficient measurement curtain from HSRL-2 for a portion of a flight on 17 July 2014 in and around Denver, Colorado. Approximately the first third of the pictured curtain is a southbound track between the Boulder Atmospheric Observatory Tall Tower and Chatfield State Park, CO. The remainder of the flight is a northbound leg between Chatfield State Park and Fort Collins. The blank region indicates a tight turn at Chatfield State Park where the lasers were shuttered. Scattered clouds are visible at the top of the boundary layer. Some of these have off-scale backscatter values (tan color) and some are thick enough to cause significant attenuation of the beam; beneath these, data are blanked out due to low signal. The white line indicates underlying terrain. The smoke layer at approximately $8 \mathrm{~km}$ is discussed in the text.

The observations by HSRL-2 in Figs. 12 and 13 are, to our knowledge, the first reported three-wavelength measurements of linear particle depolarization ratio from pure smoke. Note that while the $532 \mathrm{~nm}$ particle depolarization ratio for the smoke case is only about $25-30 \%$ of the value for pure dust, the large particle depolarization ratio at $355 \mathrm{~nm}$ for the smoke layer is quite comparable to the $355 \mathrm{~nm}$ value for dust. 


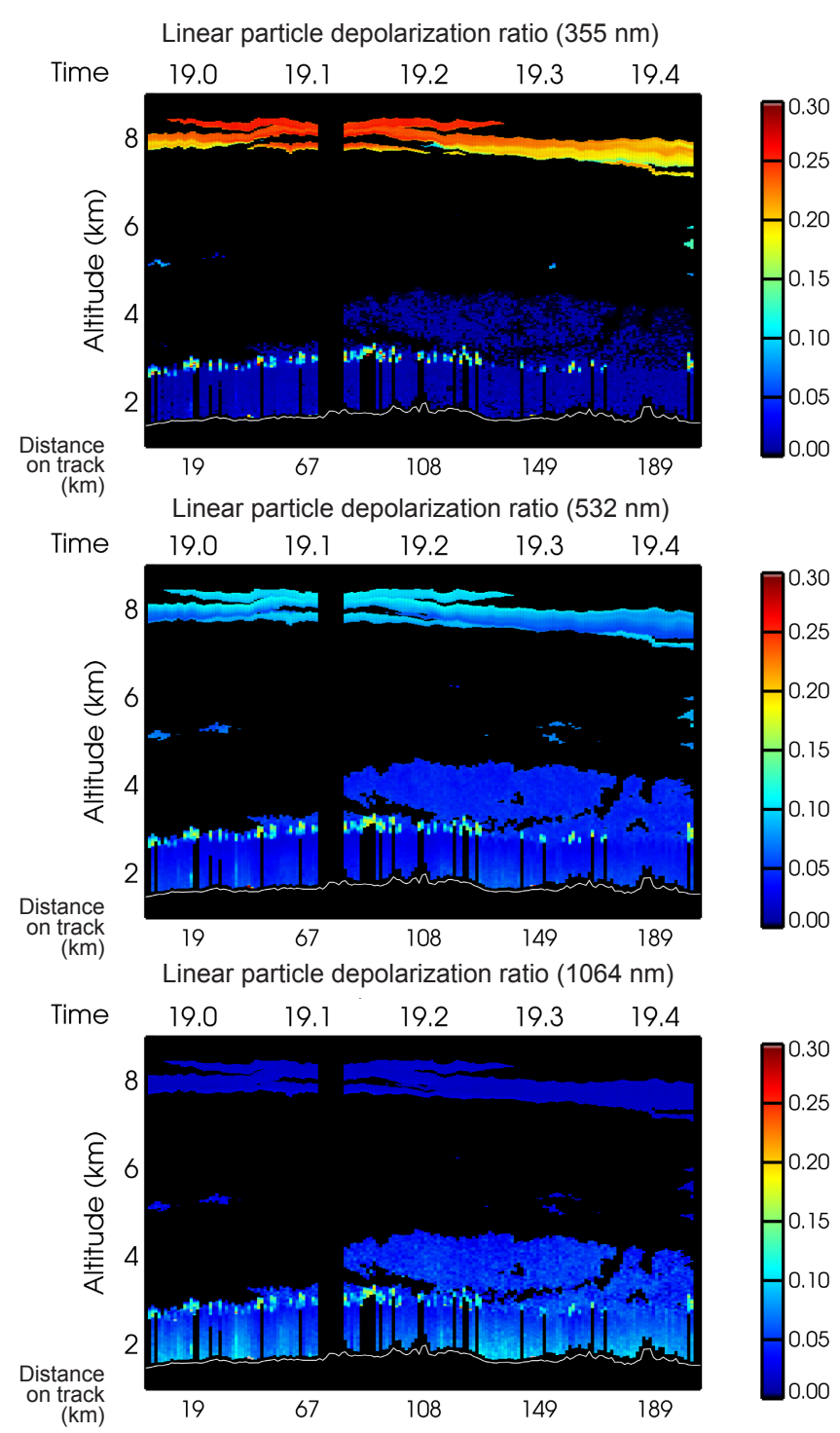

Figure 13. The linear particle depolarization ratio measurement curtains for the flight segment shown in Fig. 12.

\subsection{Discussion of the particle depolarization ratio of smoke}

Observed linear particle depolarization ratios for smoke are quite variable. Frequently, the $532 \mathrm{~nm}$ particle depolarization ratio is observed to be only a few percent at most and often discounted as negligibly close to zero (e.g., Mattis et al., 2003; Müller et al., 2005). For example, small values of about $2-3 \%$ at $532 \mathrm{~nm}$ were observed by HSRL-1 in smoke plumes in Mexico City during the Megacity Initiative: Local and Global Research Observations (MILAGRO) field mission described by de Foy et al. (2011). In the published images of HSRL-1 measurements, the smoke plumes are obvious as local minima in the particle depolarization ratio compared to the relatively high ambient values, which are due to regional dusty background conditions. However, higher values of the particle depolarization ratio at $532 \mathrm{~nm}$ of $0.05-0.11$ have sometimes been observed in aged smoke layers, e.g., 0.07 observed by HSRL-1 on 2 August 2007 noted above (Burton et al., 2012), 0.06-0.11 for transported Canadian smoke reported in Lindenberg, Germany, during the Lindenberg Aerosol Characterization Experiment (LACE) 1998 by Fiebig et al. (2002), 0.06 to 0.08 for 3-4 day old smoke from North America observed over Germany in 2011 by Dahlkötter et al. (2014), 0.06 for transported Siberian smoke observed in Tokyo in 2003 by Murayama et al. (2004), and 0.05 for Alaskan forest fire smoke observed by Sassen and Khvorostyanov (2008) in 2004. Sugimoto et al. (2010) discuss a case in which much higher $532 \mathrm{~nm}$ particle depolarization ratios were observed for smoke from a Mongolian forest fire transported to Japan in 2007. The particle depolarization ratios measured for this smoke were $0.12,0.14$, and 0.15 for layers at two different altitudes observed at Nagasaki and Tsukuba. Nisantzi et al. (2014) observe values of 0.09 to 0.18 at $532 \mathrm{~nm}$ for aerosol from Turkish fires observed in Cyprus after 1 to 4 days of transport.

The causes of depolarization by smoke are not well understood. Two possible explanations are frequently cited in literature: lifting and entrainment of surface soil into the smoke plume and asymmetry of smoke particles themselves.

For example, the smoke observed by Sugimoto et al. (2010) was associated with pyrocumulonimbus and therefore it is inferred that strong convection lifted soil particles from the surface into the smoke plume, explaining the unusually large particle depolarization ratios. Lifting of soil particles is also cited as a possible explanation of the more moderate but still non-negligible particle depolarization ratios reported by Fiebig et al. (2002), since chemical composition analysis of this plume reveals the presence of aluminosilicates and iron oxides/hydroxides. Nisantzi et al. (2014) assume that the depolarization is due to fine-mode dust and infer the mass fraction of dust mixed in the smoke plumes using lab measurements of fine and coarse dust by Sakai et al. (2010). However, this explanation is not sufficient in every case. Murayama et al. (2004) discount soil lifting for their observations of depolarizing smoke, since no signature of mineral dust is found in a chemical analysis of this plume. Instead, they cite non-sphericity of smoke particle aggregates as the probable cause. Martins et al. (1998) discuss the nonsphericity of smoke particles observed by scanning electron microscope images and an electro-optical aerosol asymmetry analyzer for a variety of smoke types during the Smoke, Clouds, and Radiation - Brazil (SCAR-B) project in 1995. They concluded that most of the non-spherical particles in the observed smoke were chain aggregates of small black carbon particles, and that the non-sphericity tends to increase with the black carbon ratio. Young smoke $(<1 \mathrm{~h})$ is composed of open clusters of high non-sphericity while aged smoke is composed of tighter clusters with lesser non-sphericity. They also point out that flaming fires (high combustion efficiency) 


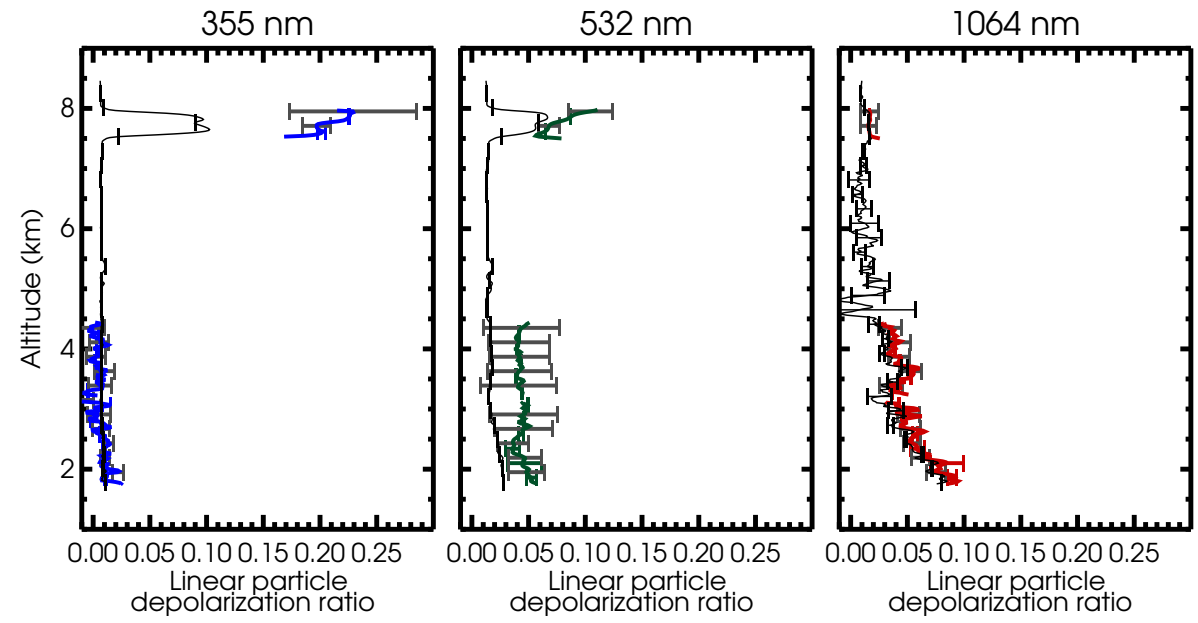

Figure 14. Line plots illustrating the volume and linear particle depolarization ratio profile for the HSRL-2 measurements at 19:18 UT (19.3 UT) on 17 July 2014. Error bars and resolutions as described for Fig. 5.

tend to produce more non-spherical particles than smoldering fires.

Referring back to the theoretical calculations of spectral depolarization for spheroids discussed in Sect. 3.3., the larger particle depolarization ratio at $355 \mathrm{~nm}$ compared to longer wavelengths may indicate a smaller size for the non-spherical particles than the dust cases, although of course these results may be only qualitatively applicable to more general particle shapes.

Theoretical calculations of the linear particle depolarization ratio by aggregates of soot are given by, e.g., Sorensen (2001), Bescond et al. (2013), and Kahnert et al. (2012). Calculations for bare carbon aggregates (Sorensen, 2001; Bescond et al., 2013) tend to produce small values of the particle depolarization ratio, much smaller than what was measured in the HSRL-2 case study. However, Kahnert et al. (2012) modeled the scattering properties of a more realistic particle morphology, light absorbing carbon (LAC) aggregates embedded in a sulfate shell, and obtain larger values. They use the discrete dipole method to calculate the depolarization ratio of the aggregate particle in the backscatter direction at 304.0, 533.2, and $1010.1 \mathrm{~nm}$. They show that the particle depolarization ratio generally increases with aggregate particle radius (defined as volume-equivalent radius) and with the volume fraction of LAC in the aggregate. The values also increase with decreasing wavelength for aggregate volume-equivalent radii of $400 \mathrm{~nm}$ and smaller; conversely, for $500 \mathrm{~nm}$ particles, the particle depolarization ratio peaks at the middle wavelength, $533.2 \mathrm{~nm}$. The maximum calculated particle depolarization ratios for $7 \%$ LAC fraction by volume is $0.08-0.11$ for $500 \mathrm{~nm}$ particles at $533.2 \mathrm{~nm}$. This is comparable to the $532 \mathrm{~nm}$ measurement on 17 July 2014; however, the calculated value at $304.0 \mathrm{~nm}$ for the same size and LAC volume fraction is $0.05-0.07$, much smaller than the measured value (at $355 \mathrm{~nm}$ ) of 0.24 . The largest values calculated for the $304.0 \mathrm{~nm}$ wavelength are about $0.12-0.21$, occurring for the case of $400 \mathrm{~nm}$ particle volume-equivalent radius and $20 \%$ LAC volume fraction. The full set of theoretical calculations of the particle depolarization ratio for $20 \%$ LAC volume fraction are replotted in Fig. 15 for all three wavelengths to highlight the wavelength dependence. Figure 15 also indicates the HSRL-2 observed particle depolarization ratio in the 17 July smoke plume (at 355,532 , and $1064 \mathrm{~nm}$ ). The calculated particle depolarization ratios are roughly comparable in magnitude to the HSRL-2 measurements for volumeequivalent radii in the $400-500 \mathrm{~nm}$ range, but the wavelength dependence matches better for smaller particle sizes. A LAC volume fraction of $20 \%$ is quite high and may be unrealistic for this smoke layer and the modeled single scattering albedos for a $20 \%$ LAC volume fraction, shown by Kahnert et al. (2012), are quite low (below 0.7 at $533.2 \mathrm{~nm}$ ), indicating exceptionally absorbing particles; therefore, this model is probably not an exact match for the observation in this case. Yet, it is encouraging that an estimate of the particle depolarization ratio of the right magnitude can be made by modeling coated soot aggregates. The model results were for a constant fractal dimension of 2.6, structural prefactor of 1.2, and a monomer radius of $25 \mathrm{~nm}$, values chosen to be consistent with the findings for soot aerosol in Mexico City (Adachi and Buseck, 2008). In the HSRL-2 case study, there could be a different fractal dimension, different size monomer component, different coating, or a different fraction of soot per aggregate. In addition, the spectral dependence of the refractive index is not well-known, and this will have a significant effect on the spectral dependence of the particle depolarization ratio. While the current state of knowledge is not sufficient to perform a retrieval of particle size using the depolarization measurements alone, it is certainly worth noting that the particle depolarization ratio at three wavelengths is sensitive to and contains some information about the particle size of 


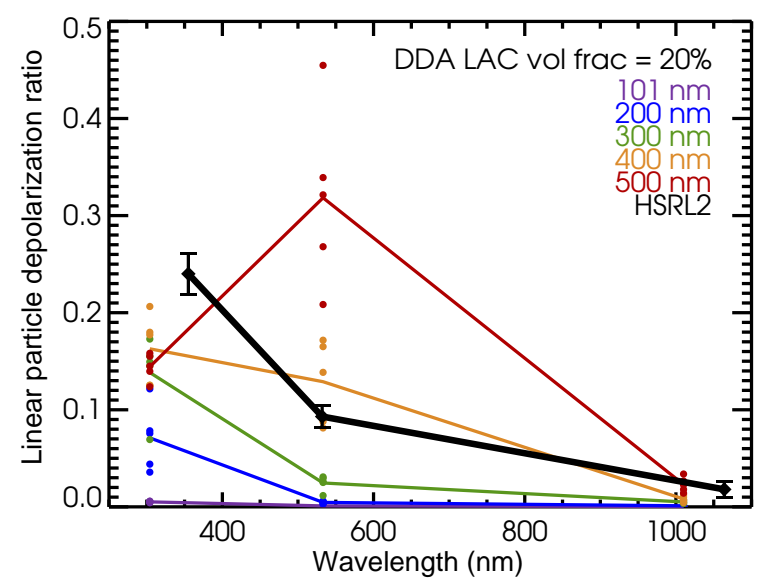

Figure 15. The linear particle depolarization ratio at three wavelengths for soot aggregates embedded in a sulfate shell reproduced from Kahnert et al. (2012), for $20 \%$ LAC volume fraction. Dots indicate five realizations with randomly generated geometries, per aggregate volume-equivalent particle radius. The colored lines connect the averages of the five for each wavelength. The legend shows the aggregate volume-equivalent particle radii at which the calculation was performed. The thick black line indicates the particle depolarization ratios measured by airborne HSRL-2 within a smoke plume observed on 17 July 2014 at 355, 532, and $1064 \mathrm{~nm}$.

smoke particles, information that may play a role in future microphysical retrievals.

\section{Summary and discussion}

We have presented three case studies of depolarizing aerosol observed at three wavelengths $(355,532$ and $1064 \mathrm{~nm})$ by the NASA airborne HSRL-2 instrument. These three aerosol layers, two dust-dominated layers and a smoke layer, each have a different spectral dependence of the linear particle depolarization ratio, but in each case, the 532 and $1064 \mathrm{~nm}$ values agree well with prior analogs in the long record of observations by the predecessor instrument, HSRL-1, and with comparable measurements in literature. The first case, transported Saharan desert aerosol, has a peak in the spectral dependence of the particle depolarization ratio at $532 \mathrm{~nm}$. This is in accordance with prior measurements of Saharan desert aerosol aloft both close to the source and transported to the Caribbean Sea. The second case, also a dust-dominated measurement, but near the surface and very close to the source, has a spectral dependence increasing monotonically with wavelength, differing from the previous case primarily at the longest wavelength, $1064 \mathrm{~nm}$. We infer the cause of this difference to be a greater fraction of very large particles due to its proximity to the source region; we believe that the largest particles have settled out of the observed Saharan layers but not the locally produced North American dust plumes in this case and a prior HSRL-1 case. Our third case study is of an elevated, transported smoke layer and has a spectral depolarization ratio decreasing monotonically with wavelength. Again we infer that the difference in spectral dependence is due to the size of the non-spherical particles, and, specifically, that the depolarization is probably due to smoke aerosols and may be explained by soot aggregates.

Microphysical retrievals (Müller et al., 2014) were not available for these HSRL-2 measurement cases, because the current state of these retrievals is limited to spherical particles. However, as suggested by Gasteiger and Freudenthaler (2014) for dust and ash, these observations suggest the possibility that the particle depolarization ratio measurements may aid in retrievals of particle size of non-spherical dust and smoke particles in the future.

More immediately, since the upcoming EarthCARE satellite mission will include a lidar instrument that measures the particle depolarization ratio and lidar ratio at $355 \mathrm{~nm}$ only, it is valuable to have measurements of the spectral dependence of depolarization ratio for depolarizing aerosol types. These data will help to build the basis for comparing observations from EarthCARE to existing measurements at $532 \mathrm{~nm}$ from the CALIPSO satellite. Studying such correspondence is particularly motivated by the desire to identify different aerosol types observed by the EarthCARE satellite. The particle depolarization ratio is hoped to be particularly useful for distinguishing dust and ash from smoke and other aerosol types (Groß et al., 2014; Illingworth et al., 2015), as it already is for CALIPSO (Omar et al., 2009).

However, as illustrated by the case studies presented here, there is not a single consistent spectral dependence of the particle depolarization ratio. On the positive side (from the perspective of corresponding CALIPSO and EarthCARE measurements), for aerosols dominated by dust the 355 and $532 \mathrm{~nm}$ particle depolarization ratios appear to be fairly consistent even for different particle sizes and may be relatively easily converted. Variation in the 532 and $355 \mathrm{~nm}$ particle depolarization ratios for dusty aerosols has been primarily linked to the fraction of dust particles in a sample (Sugimoto et al., 2003); therefore, there is no reason to think that inferences of dust mixing ratios (e.g., Sugimoto and Lee, 2006; Tesche et al., 2009a; Nishizawa et al., 2011; Burton et al., 2014) may not be done with $355 \mathrm{~nm}$ measurements. However, in the case of dust-dominated aerosol, the $355 \mathrm{~nm}$ signal consistently is significantly both smaller and more difficult to measure accurately than the $532 \mathrm{~nm}$ signal, and therefore the signature of dust may be harder to detect from space at $355 \mathrm{~nm}$ than at $532 \mathrm{~nm}$ for dilute dust mixtures.

On the other hand, the third case study presented here showed that the smoke particle depolarization ratio can be significantly larger at $355 \mathrm{~nm}$ than at $532 \mathrm{~nm}$, and in fact the particle depolarization ratio at $355 \mathrm{~nm}$ for this smoke case was quite comparable to the dust-dominated cases. If this is not an isolated case, and this signature proves typical for some subsets of smoke aerosol in particular conditions, the EarthCARE satellite may observe significant par- 
Table 2. Illustrates the systematic uncertainty in the linear particle depolarization ratio propagated from the systematic uncertainties in total aerosol scattering ratio, linear volume depolarization ratio, and linear molecular depolarization ratio. Benchmark values of $R$ (total aerosol scattering ratio), $\delta_{\text {tot }}$ (the volume depolarization ratio) and $\delta_{\text {mol }}$ (the molecular depolarization ratio) and typical systematic uncertainties are given in the first three columns. Columns 4-6 give the propagation factors, as described in the text. Column 7 gives the resulting particle depolarization ratio and systematic uncertainty for each benchmark set. Note: percentages given in this table are relative uncertainties (not depolarization ratio units).

\begin{tabular}{lrrrrrr}
\hline$R$ & $\delta_{\text {tot }}$ & $\delta_{\mathrm{m}}$ & $F_{\mathrm{R}}$ & $F_{\delta \text { tot }}$ & $F_{\delta m}$ & $\delta_{\mathrm{a}}$ \\
\hline $3.0 \pm 5 \%$ & $0.15 \pm 5 \%$ & $0.0036 \pm 1 \%$ & 0.37 & 1.2 & $1 \times 10^{-4}$ & $0.24 \pm 6 \%$ \\
$3.0 \pm 5 \%$ & $0.05 \pm 5 \%$ & $0.0036 \pm 1 \%$ & 0.26 & 1.1 & $8 \times 10^{-4}$ & $0.07 \pm 6 \%$ \\
$2.0 \pm 5 \%$ & $0.2 \pm 5 \%$ & $0.0036 \pm 1 \%$ & 2.2 & 1.6 & $3 \times 10^{-4}$ & $0.49 \pm 10 \%$ \\
$2.0 \pm 5 \%$ & $0.1 \pm 5 \%$ & $0.0036 \pm 1 \%$ & 1.4 & 1.3 & $6 \times 10^{-4}$ & $0.22 \pm 8 \%$ \\
$2.0 \pm 5 \%$ & $0.05 \pm 5 \%$ & $0.0036 \pm 1 \%$ & 1.1 & 1.2 & 0.002 & $0.10 \pm 8 \%$ \\
$1.2 \pm 5 \%$ & $0.05 \pm 5 \%$ & $0.0036 \pm 1 \%$ & 45 & 1.9 & 0.008 & $0.37 \pm 34 \%$ \\
\hline
\end{tabular}

ticle depolarization in some types of smoke as well as in dust-dominated aerosol. If this is the case, global observations of smoke depolarization will present an exciting opportunity for improving our understanding of the optical properties of smoke and how they change with age and processing; however, it will also present a challenge. That is, a significant particle depolarization ratio signature at the single wavelength of $532 \mathrm{~nm}$ has been sufficient for distinguishing dust-dominated aerosol from smoke aerosol, but at $355 \mathrm{~nm}$ this signature by itself is more ambiguous, if the smoke case presented here is not an isolated case. EarthCARE will also measure the lidar ratio at $355 \mathrm{~nm}$; this is related to absorption but has significant variability for smoke (Groß et al., 2014). EarthCARE will not have backscatter or extinction measurements at a second wavelength to give an indicator of particle size. Therefore, for any cases where the particle depolarization ratio is ambiguous, smoke and dust may not be easily separable. 


\section{Appendix A: Systematic uncertainties}

In Sect. 2.2 we provided systematic uncertainties in the linear volume depolarization ratio of the larger of $4.7 \%$ (relative) or 0.001 (absolute) in the $355 \mathrm{~nm}$ channel, the larger of $5 \%$ (relative) or 0.007 (absolute) in the $532 \mathrm{~nm}$ channel, and the larger of $2.6 \%$ (relative) or 0.007 (absolute) in the $1064 \mathrm{~nm}$ channel. For $R$ (total aerosol scattering ratio) we estimate the systematic uncertainty to be $4.1 \%$ for the $532 \mathrm{~nm}$ channel, $5 \%$ for the 355 channel, and $20 \%$ for the $1064 \mathrm{~nm}$ channels. The systematic uncertainties are estimated conservatively as confidence limits, such that we expect a high probability that the true systematic error is within this uncertainty. Here in the Appendix, we discuss the error sources and estimates of the uncertainties in more detail.

For the linear volume depolarization ratio, potential sources of systematic error include an error in the polarization gain ratio calibration or cross talk between the copolarized and cross-polarized signals. The polarization gain ratio calibration generally occurs once or twice per flight as described above in Sect. 2.1. Since gain ratios can potentially change during a flight, due to temperature changes for example, our best estimate of uncertainty in the gain ratio during a flight is obtained by examining the change in the gain ratio between successive calibrations in the same flight. Conservatively choosing the mean difference plus 2 standard deviations (calculated for all flights with at least two calibrations per flight in the most recent field campaign) as a realistic limit on the probable polarization gain ratio systematic error yields $4.7 \%$ uncertainty for the $355 \mathrm{~nm}$ channel, $5.0 \%$ for the $532 \mathrm{~nm}$ channel, and $2.6 \%$ for the $1064 \mathrm{~nm}$ channel. The relative systematic uncertainty from the polarization gain ratio propagates directly to the volume depolarization ratio, since the volume depolarization ratio is linearly related to the polarization gain ratio.

Residual cross talk is known to occur in polarization lidars, and must be carefully characterized and eliminated as much as possible. A well-known potential source of cross talk occurs in the reflected channel from a polarization beam splitter. Therefore, this system has been designed with extra polarization beam splitters to eliminate that potential concern, as described in Sect. 2.1 and illustrated in Fig. 2. Clearair studies have found a small residual cross talk, which appears as a value of the clear-air volume depolarization ratio that exceeds the theoretical (molecular-only) value. As described in Sect. 2.1, the narrow bandwidths in the system completely eliminate the rotational Raman scattering sidebands, and so the molecular depolarization ratio is temperature independent and is calculated to be 0.0036 using $\mathrm{N}_{2}$ and $\mathrm{O}_{2}$ molecules (ignoring a negligible wavelength dependence due to non-linear molecules like $\mathrm{CO}_{2}$ ) (Behrendt and Nakamura, 2002). Since 2006, we have historically measured minimum depolarization ratios in clear air that exceed the theoretical value, namely values of approximately 0.006 in the $355 \mathrm{~nm}$ channel, approximately 0.008 in the $1064 \mathrm{~nm}$ chan- nel, and $0.0085-0.0135$ in the $532 \mathrm{~nm}$ channel, which we attribute to a small remaining ellipticity in the optics or stress birefringence in the aircraft window. Cross talk due to ellipticity in the transmission system can be modeled, as follows.

We start with the polarization Stokes vector (Born and Wolf, 1999)

$\boldsymbol{S}=\left(\begin{array}{c}1 \\ \cos (2 \theta) \cos (2 \psi) \\ \cos (2 \theta) \sin (2 \psi) \\ \sin (2 \theta)\end{array}\right)$,

where the angles $\theta$ and $\psi$ represent the ellipticity angle and polarization offset angle, plus the Mueller matrix for a partially depolarizing backward scattering process (Mishchenko and Hovenier, 1995; Gimmestad, 2008),

$\hat{\mathbf{M}}=\left(\begin{array}{cccc}1 & 0 & 0 & 0 \\ 0 & 1-\frac{2 \delta_{\mathrm{tot}}}{\delta_{\mathrm{tot}}+1} & 0 & 0 \\ 0 & 0 & \frac{2 \delta_{\mathrm{tot}}}{\delta_{\mathrm{tot}}+1}-1 & 0 \\ 0 & 0 & 0 & \frac{4 \delta_{\mathrm{tot}}}{\delta_{\mathrm{tot}}+1}-1\end{array}\right)$.

Assuming there is a polarization offset angle (rotation) or ellipticity in the transmission, we derive the correction to the measured depolarization ratio to be

$\delta_{\text {corr }}=\frac{\delta_{\text {meas }}+\chi+\chi \delta_{\text {meas }}-1}{\chi-\delta_{\text {meas }}+\chi \delta_{\text {meas }}+1}$,

where

$\chi=\cos (2 \theta) \cos (2 \psi)$.

The subscript "meas" indicates the measured depolarization ratio and "corr" represents the corrected depolarization ratio, assuming the measurement to be affected by cross talk, caused by ellipticity or an angle offset, or both. Equations (A3) and (A4) make no distinction between the ellipticity and polarization offset angles $\theta$ and $\psi$. Therefore, we can model cross talk due to either source using the same correction, although noting that an offset angle would additionally affect the polarization gain ratio, treated separately. Equation (A3) represents a fairly constant shift in the volume depolarization ratio approximately equal to the offset between the measured clear-air value and the molecular-only depolarization ratio. An ellipticity angle of $5.8^{\circ}(\chi=0.980)$ would explain the error in the depolarization ratio at $532 \mathrm{~nm}$ where the error is largest. A partial correction for the cross talk was implemented in the archived HSRL-2 data (a full correction as in Eq. (A3) will be included in the next version of processed HSRL-2 data). Taking the partial correction into account, we include a component of 0.007 (absolute) due to cross talk in the estimated volume depolarization ratio error for the 532 and $1064 \mathrm{~nm}$ channels and 0.001 (absolute) for the $355 \mathrm{~nm}$ channel.

We believe that the polarization angle error is much smaller than the inferred angle of $5.8^{\circ}$. The angle calibration procedure has been carefully designed and used successfully on both the HSRL-1 and HSRL-2 systems since 2006, 
and the accuracy of the polarization angle is high. The polarization angle calibration indicates the zero point of the wave-plate angle where the polarization of the detector is properly aligned compared to the transmitted beams; if the wave plate was not already set at this zero point it is then rotated to that point for subsequent science measurements. Adjustments indicated during polarization angle calibrations are at most $0.4^{\circ}$ of polarization $\left(0.2^{\circ}\right.$ rotation of the halfwave plate) for all channels (assessed, as before, using the mean plus 2 standard deviations for all flights having multiple polarization angle calibrations during the latest field mission), which is a good indicator of the systematic uncertainty in the polarization angle for measurements between calibrations. Since the polarization angle calibration error is much smaller than the inferred ellipticity $\left(0.4^{\circ}\right.$ compared to $\left.6^{\circ}\right)$, we do not include polarization angle calibration directly in the systematic uncertainty budget.

Note that not only the volume depolarization ratio measurement itself but also the polarization gain ratio calibration depend on the correct alignment of the calibration wave plates in Fig. 1. The polarization gain ratio assessment depends on a polarization alignment of $45^{\circ}$ during calibration. This effect on the measured gain will be reflected in the error of the gain ratio, and therefore is already included in the polarization gain ratio systematic uncertainty discussed above.

The calculated particle depolarization ratio, $\delta_{\mathrm{a}}$, is additionally affected by any errors in the total aerosol scattering ratio, $R$, in Eq. (2). For $532 \mathrm{~nm}$, the only significant potential systematic error in $R$ is an error in the gain ratio between the aerosol and molecular channels. The uncertainty of the aerosol-to-molecular gain ratio was assessed in a similar manner to the offset angle and polarization gain ratios given above, by examining the change in the gain ratio on flights where multiple aerosol-to-molecular gain calibrations occurred during a flight. The uncertainty in the $532 \mathrm{~nm}$ aerosol-to-molecular gain ratio is estimated to be $4.1 \%$. A systematic uncertainty of $4.1 \%$ in the aerosol-to-molecular gain ratio propagates directly to a $4.1 \%$ uncertainty in $R$ for the $532 \mathrm{~nm}$ channel, since the aerosol-to-molecular gain ratio and the total aerosol scattering ratio are linearly related.

The 355 and $1064 \mathrm{~nm}$ channels are somewhat more complicated, because it is not possible to calibrate them directly in the same way as $532 \mathrm{~nm}$. The iodine filter for the $532 \mathrm{~nm}$ HSRL channel allows for essentially complete separation of the aerosol signal from the total (aerosol plus molecular) signal, but this is not the case for the interferometer used at $355 \mathrm{~nm}$, and the $1064 \mathrm{~nm}$ channel has only one total channel with no separation. So for these channels, the calibration is transferred from $532 \mathrm{~nm}$ in a cloud-free region in the free troposphere, as described by Hair et al. (2008). In the calibration transfer region, we do not assume that there is no aerosol, but do look for regions where the aerosol backscatter ratio is small and can be inferred from the value at $532 \mathrm{~nm}$ assuming a constant backscatter Ångström exponent. By using a range of reasonable backscatter Ångström exponents, we conservatively estimate an uncertainty of $3 \%$ in total aerosol scattering ratio for the $355 \mathrm{~nm}$ channel. The $1064 \mathrm{~nm}$ aerosol backscatter ratio is also affected by the assumption of the lidar ratio to use for separating the aerosol and molecular part; this sensitivity is relatively small for backscatter at $1064 \mathrm{~nm}$, compared to shorter wavelengths or compared to the sensitivity of extinction. Taking these sources into account, we conservatively use $20 \%$ as the uncertainty in total aerosol scattering ratio, $R$, at $1064 \mathrm{~nm}$.

For the $355 \mathrm{~nm}$ channel, the system implements an interferometer to spectrally separate the aerosol and molecular scattering components. The ratio of the aerosol signal in the aerosol-dominated channel to the aerosol signal in the molecular-dominated channel is referred to as the contrast ratio, which needs to be determined to accurately derive the total aerosol scattering ratio. For the HSRL-2 system, fairly high contrast ratios of 15-20 are routinely achieved. Our estimate of the error in the contrast ratio definition is usually a few percent but can be up to $20 \%$. A $20 \%$ error in the contrast ratio for the smoke case presented here would produce an error in the total aerosol scattering ratio of less than $4 \%$. Adding the contrast ratio uncertainty, $4 \%$, and the calibration transfer uncertainty, $3 \%$, in quadrature yields an uncertainty of $5 \%$ for the $355 \mathrm{~nm}$ total aerosol scattering ratio.

The uncertainties given above are intended to be an upper bound on the probable systematic errors. The systematic errors on the three quantities, $\delta_{\mathrm{mol}}, \delta_{\mathrm{tot}}$, and $R$, are independent and, since their actual values within these uncertainty estimates are unknown, they should be treated statistically. We therefore combine the three sources of systematic uncertainty in quadrature to assess the systematic uncertainty in the particle depolarization ratio, $\delta_{\mathrm{a}}$. The propagation is described by the following equation

$$
\left(\frac{\Delta \delta_{\mathrm{a}}}{\delta_{\mathrm{a}}}\right)^{2}=F_{\mathrm{R}}\left(\frac{\Delta R}{R}\right)^{2}+F_{\mathrm{tot}}\left(\frac{\Delta \delta_{\mathrm{tot}}}{\delta_{\mathrm{tot}}}\right)^{2}+F_{\mathrm{m}}\left(\frac{\Delta \delta_{\mathrm{m}}}{\delta_{\mathrm{m}}}\right)^{2} .
$$

Here, the $\Delta$ symbol indicates the systematic uncertainty associated with the various quantities and the propagation factors $F_{x}$ are defined like this:

$F_{x}=\left(\frac{x}{\delta_{\mathrm{a}}} \frac{\partial \delta_{\mathrm{a}}}{\partial x}\right)^{2}$

The partial derivatives are calculated easily from Eq. (2), which relates the particle depolarization ratio to the factors $R, \delta_{\text {tot }}$, and $\delta_{\mathrm{m}}$. From Eq. (A5), the propagation factors, $F_{x}$, are the factors by which the relative uncertainty in the particle depolarization ratio is magnified with respect to the relative uncertainty in the component variables.

These factors vary with total aerosol scattering ratio and volume depolarization ratio but do not depend on the systematic uncertainties. To illustrate the behavior of the particle depolarization ratio systematic uncertainty, Table 2 gives the value of the particle depolarization ratio and its propagated systematic uncertainty (as a percent error) for bench- 
mark values of the total aerosol scattering ratio and the volume and molecular depolarization ratios, plus their estimated systematic uncertainties. It also gives the propagation factors, $F_{x}$. From Table 2, it is clear that the propagation factor for the uncertainty in the molecular depolarization ratio is always small, the propagation factor for the volume depolarization ratio uncertainty is typically $1-2$, and the propagation factor for uncertainty in the total aerosol scattering ratio, $F_{\mathrm{R}}$, varies significantly with the total aerosol scattering ratio. $F_{\mathrm{R}}$ is comparable to $F_{\text {tot }}$ except when the total aerosol scattering ratio is fairly small; in the case of small scattering, it is significantly larger. 
Acknowledgements. Funding for this research came from the NASA HQ Science Mission Directorate Radiation Sciences Program and the DISCOVER-AQ project. M. Kahnert acknowledges funding by the Swedish Research Council (Vetenskapsrådet) under project 621-2011-3346. The authors also acknowledge the NOAA Air Resources Laboratory (ARL) for the provision of the HYSPLIT transport and dispersion model and READY web site (http://www.arl.noaa.gov/ready.php) used for some of the analysis described in this work. The MODIS images used in Fig. 7 were obtained from the MODIS Adaptive Processing System (MODAPS) archive. Thank you to Rich Hare and Terry Mack of the NASA Langley Engineering Directorate for their exceptional work on the HSRL-2 instrument. The authors are also very grateful to the NASA Langley B200 King Air crew from the California and Colorado deployments: Mike Basnett, Dale Bowser, Les Kagey, Howie Lewis, Scott Sims, Mike Wusk, and Rick Yasky from LaRC and also Kurt Blankenship and Munro Dearing for their dedication in support of HSRL measurements.

Edited by: M. Tesche

\section{References}

Adachi, K. and Buseck, P. R.: Internally mixed soot, sulfates, and organic matter in aerosol particles from Mexico City, Atmos. Chem. Phys., 8, 6469-6481, doi:10.5194/acp-8-6469-2008, 2008.

Alvarez, J. M., Vaughan, M. A., Hostetler, C. A., Hunt, W. H., and Winker, D. M.: Calibration Technique for PolarizationSensitive Lidars, J. Atmos. Ocean. Tech., 23, 683-699, doi:10.1175/jtech1872.1, 2006.

Ansmann, A., Tesche, M., Knippertz, P., Bierwirth, E., Althausen, D., Muller, D., and Schulz, O.: Vertical profiling of convective dust plumes in southern Morocco during SAMUM, Tellus Ser. B-Chem. Phys. Meteorol., 61, 340-353, doi:10.1111/j.16000889.2008.00384.x, 2009.

Ansmann, A., Tesche, M., Seifert, P., Groß, S., Freudenthaler, V., Apituley, A., Wilson, K. M., Serikov, I., Linné, H., Heinold, B., Hiebsch, A., Schnell, F., Schmidt, J., Mattis, I., Wandinger, U., and Wiegner, M.: Ash and fine-mode particle mass profiles from EARLINET-AERONET observations over central Europe after the eruptions of the Eyjafjallajökull volcano in 2010, J. Geophys. Res.-Atmos., 116, D00U02, doi:10.1029/2010JD015567, 2011.

Ansmann, A., Seifert, P., Tesche, M., and Wandinger, U.: Profiling of fine and coarse particle mass: case studies of Saharan dust and Eyjafjallajökull/Grimsvötn volcanic plumes, Atmos. Chem. Phys., 12, 9399-9415, doi:10.5194/acp-12-9399-2012, 2012.

Behrendt, A. and Nakamura, T.: Calculation of the calibration constant of polarization lidar and its dependency on atmospheric temperature, Opt. Express, 10, 805-817, doi:10.1364/OE.10.000805, 2002.

Bescond, A., Yon, J., Girasole, T., Jouen, C., Rozé, C., and Coppalle, A.: Numerical investigation of the possibility to determine the primary particle size of fractal aggregates by measuring light depolarization, J. Quant. Spectrosc. Ra., 126, 130-139, 2013.

Born, M. and Wolf, E.: Principles of optics: electromagnetic theory of propagation, interference and diffraction of light, Cambridge university press, 29-32, 1999.
Burton, S. P., Ferrare, R. A., Hostetler, C. A., Hair, J. W., Rogers, R. R., Obland, M. D., Butler, C. F., Cook, A. L., Harper, D. B., and Froyd, K. D.: Aerosol classification using airborne High Spectral Resolution Lidar measurements - methodology and examples, Atmos. Meas. Tech., 5, 73-98, doi:10.5194/amt-5-73-2012, 2012.

Burton, S. P., Ferrare, R. A., Vaughan, M. A., Omar, A. H., Rogers, R. R., Hostetler, C. A., and Hair, J. W.: Aerosol classification from airborne HSRL and comparisons with the CALIPSO vertical feature mask, Atmos. Meas. Tech., 6, 13971412, doi:10.5194/amt-6-1397-2013, 2013.

Burton, S. P., Vaughan, M. A., Ferrare, R. A., and Hostetler, C. A.: Separating mixtures of aerosol types in airborne High Spectral Resolution Lidar data, Atmos. Meas. Tech., 7, 419-436, doi:10.5194/amt-7-419-2014, 2014.

Cairo, F., Di Donfrancesco, G., Adriani, A., Pulvirenti, L., and Fierli, F.: Comparison of Various Linear Depolarization Parameters Measured by Lidar, Appl. Opt., 38, 4425-4432, 1999.

Dahlkötter, F., Gysel, M., Sauer, D., Minikin, A., Baumann, R., Seifert, P., Ansmann, A., Fromm, M., Voigt, C., and Weinzierl, B.: The Pagami Creek smoke plume after long-range transport to the upper troposphere over Europe - aerosol properties and black carbon mixing state, Atmos. Chem. Phys., 14, 6111-6137, doi:10.5194/acp-14-6111-2014, 2014.

David, G., Thomas, B., Nousiainen, T., Miffre, A., and Rairoux, P.: Retrieving simulated volcanic, desert dust and sea-salt particle properties from two/three-component particle mixtures using UV-VIS polarization lidar and T matrix, Atmos. Chem. Phys., 13, 6757-6776, doi:10.5194/acp-13-6757-2013, 2013.

de Foy, B., Burton, S. P., Ferrare, R. A., Hostetler, C. A., Hair, J. W., Wiedinmyer, C., and Molina, L. T.: Aerosol plume transport and transformation in high spectral resolution lidar measurements and WRF-Flexpart simulations during the MILAGRO Field Campaign, Atmos. Chem. Phys., 11, 3543-3563, doi:10.5194/acp-11-3543-2011, 2011.

Fernald, F. G.: Analysis of Atmospheric Lidar Observations - Some Comments, Appl. Optics, 23, 652-653, 1984.

Fiebig, M., Petzold, A., Wandinger, U., Wendisch, M., Kiemle, C., Stifter, A., Ebert, M., Rother, T., and Leiterer, U.: Optical closure for an aerosol column: Method, accuracy, and inferable properties applied to a biomass-burning aerosol and its radiative forcing, J. Geophys. Res., 107, 8130, doi:10.1029/2000jd000192, 2002.

Freudenthaler, V., Esselborn, M., Wiegner, M., Heese, B., Tesche, M., Ansmann, A., Muller, D., Althausen, D., Wirth, M., Fix, A., Ehret, G., Knippertz, P., Toledano, C., Gasteiger, J., Garhammer, M., and Seefeldner, M.: Depolarization ratio profiling at several wavelengths in pure Saharan dust during SAMUM 2006, Tellus B, 61, 165-179, doi:10.1111/j.1600-0889.2008.00396.x, 2009.

Gasteiger, J. and Freudenthaler, V.: Benefit of depolarization ratio at $\lambda=1064 \mathrm{~nm}$ for the retrieval of the aerosol microphysics from lidar measurements, Atmos. Meas. Tech., 7, 3773-3781, doi:10.5194/amt-7-3773-2014, 2014.

Gasteiger, J., Wiegner, M., Groß, S., Freudenthaler, V., Toledano, C., Tesche, M., and Kandler, K.: Modelling lidar-relevant optical properties of complex mineral dust aerosols, Tellus B, 63, 725741, doi:10.1111/j.1600-0889.2011.00559.x, 2011.

Gimmestad, G. G.: Reexamination of depolarization in lidar measurements, Appl. Opt., 47, 3795-3802, 2008. 
Groß, S., Esselborn, M., Weinzierl, B., Wirth, M., Fix, A., and Petzold, A.: Aerosol classification by airborne high spectral resolution lidar observations, Atmos. Chem. Phys., 13, 2487-2505, doi:10.5194/acp-13-2487-2013, 2013.

Groß, S., Freudenthaler, V., Wirth, M., and Weinzierl, B.: Towards an aerosol classification scheme for future EarthCARE lidar observations and implications for research needs, Atmos. Sci. Lett., 16, 77-82, doi:10.1002/asl2.524, 2014.

Groß, S., Freudenthaler, V., Schepanski, K., Toledano, C., Schäfler, A., Ansmann, A., and Weinzierl, B.: Optical properties of longrange transported Saharan dust over Barbados as measured by dual-wavelength depolarization Raman lidar measurements, Atmos. Chem. Phys., 15, 11067-11080, doi:10.5194/acp-1511067-2015, 2015.

Haarig, M., Althausen, D., Ansmann, A., Klepel, A., Baars, H., Engelmann, R., and Groß, S.: Measurement of the linear depolarization ratio of aged dust at three wavelengths (355, 532 and $1064 \mathrm{~nm}$ ) simultaneously over Barbados, International Laser Radar Conference, New York, NY, 5-10 July 2015.

Hair, J. W., Hostetler, C. A., Cook, A. L., Harper, D. B., Ferrare, R. A., Mack, T. L., Welch, W., Izquierdo, L. R., and Hovis, F. E.: Airborne High Spectral Resolution Lidar for profiling aerosol optical properties, Appl. Optics, 47, 6734-6752, doi:10.1364/AO.47.006734, 2008.

Illingworth, A. J., Barker, H. W., Beljaars, A., Ceccaldi, M., Chepfer, H., Cole, J., Delanoë, J., Domenech, C., Donovan, D. P., Fukuda, S., Hirakata, M., Hogan, R. J., Huenerbein, A., Kollias, P., Kubota, T., Nakajima, T., Nakajima, T. Y., Nishizawa, T., Ohno, Y., Okamoto, H., Oki, R., Sato, K., Satoh, M., Shephard, M., Wandinger, U., Wehr, T., and van Zadelhoff, G. J.: THE EARTHCARE SATELLITE: The next step forward in global measurements of clouds, aerosols, precipitation and radiation, B. Am. Meteorol. Soc., 96, 1311-1332, doi:10.1175/BAMS-D-1200227.1, 2015.

Johnson, M. S., Meskhidze, N., and Praju Kiliyanpilakkil, V.: A global comparison of GEOS-Chem-predicted and remotelysensed mineral dust aerosol optical depth and extinction profiles, Journal of Advances in Modeling Earth Systems, 4, M07001, doi:10.1029/2011MS000109, 2012.

Kahnert, M., Nousiainen, T., Lindqvist, H., and Ebert, M.: Optical properties of light absorbing carbon aggregates mixed with sulfate: assessment of different model geometries for climate forcing calculations, Opt. Express, 20, 10042-10058, doi:10.1364/OE.20.010042, 2012.

Liu, Z., Fairlie, T. D., Uno, I., Huang, J., Wu, D., Omar, A., Kar, J., Vaughan, M., Rogers, R., Winker, D., Trepte, C., Hu, Y., Sun, W., Lin, B., and Cheng, A.: Transpacific transport and evolution of the optical properties of Asian dust, J. Quant. Spectrosc. Ra., 116, 24-33, doi:10.1016/j.jqsrt.2012.11.011, 2013.

Mamouri, R. E. and Ansmann, A.: Fine and coarse dust separation with polarization lidar, Atmos. Meas. Tech., 7, 3717-3735, doi:10.5194/amt-7-3717-2014, 2014.

Maring, H., Savoie, D. L., Izaguirre, M. A., Custals, L., and Reid, J. S.: Mineral dust aerosol size distribution change during atmospheric transport, J. Geophys. Res.-Atmos., 108, 8592, doi:10.1029/2002jd002536, 2003.

Martins, J. V., Hobbs, P. V., Weiss, R. E., and Artaxo, P.: Sphericity and morphology of smoke particles from biomass burn- ing in Brazil, J. Geophys. Res.-Atmos., 103, 32051-32057, doi:10.1029/98JD01153, 1998.

Mattis, I., Ansmann, A., Wandinger, U., and Müller, D.: Unexpectedly high aerosol load in the free troposphere over central Europe in spring/summer 2003, Geophys. Res. Lett., 30, D2178, doi:10.1029/2003g1018442, 2003.

McGill, M. J., Welton, E. J., Yorks, J. E., and Scott, V. S.: CATS: A New Earth Science Capability, in: The Earth Observer, edited by: Ward, A., 4-8, NASA Earth Observing System Project Science Office 2012.

Mishchenko, M. I. and Hovenier, J. W.: Depolarization of light backscattered by randomly oriented nonspherical particles, Opt. Lett., 20, 1356-1358, 1995.

Mishchenko, M. I. and Sassen, K.: Depolarization of lidar returns by small ice crystals: An application to contrails, Geophys. Res. Lett., 25, 309-312, 1998.

Müller, D., Mattis, I., Wandinger, U., Ansmann, A., Althausen, D., and Stohl, A.: Raman lidar observations of aged Siberian and Canadian forest fire smoke in the free troposphere over Germany in 2003: Microphysical particle characterization, J. Geophys. Res.-Atmos., 110, D17201, doi:10.1029/2004jd005756, 2005.

Müller, D., Hostetler, C. A., Ferrare, R. A., Burton, S. P., Chemyakin, E., Kolgotin, A., Hair, J. W., Cook, A. L., Harper, D. B., Rogers, R. R., Hare, R. W., Cleckner, C. S., Obland, M. D., Tomlinson, J., Berg, L. K., and Schmid, B.: Airborne Multiwavelength High Spectral Resolution Lidar (HSRL-2) observations during TCAP 2012: vertical profiles of optical and microphysical properties of a smoke/urban haze plume over the northeastern coast of the US, Atmos. Meas. Tech., 7, 3487-3496, doi:10.5194/amt-7-3487-2014, 2014.

Murayama, T., Müller, D., Wada, K., Shimizu, A., Sekiguchi, M., and Tsukamoto, T.: Characterization of Asian dust and Siberian smoke with multiwavelength Raman lidar over Tokyo, Japan in spring 2003, Geophys. Res. Lett., 31, L23103, doi:10.1029/2004g1021105, 2004.

Nisantzi, A., Mamouri, R. E., Ansmann, A., and Hadjimitsis, D.: Injection of mineral dust into the free troposphere during fire events observed with polarization lidar at Limassol, Cyprus, Atmos. Chem. Phys., 14, 12155-12165, doi:10.5194/acp-1412155-2014, 2014.

Nishizawa, T., Sugimoto, N., Matsui, I., Shimizu, A., and Okamoto, H.: Algorithms to retrieve optical properties of three component aerosols from two-wavelength backscatter and onewavelength polarization lidar measurements considering nonsphericity of dust, J. Quant. Spectrosc. Ra., 112, 254-267, doi:10.1016/j.jqsrt.2010.06.002, 2011.

Omar, A. H., Winker, D. M., Kittaka, C., Vaughan, M. A., Liu, Z. Y., Hu, Y. X., Trepte, C. R., Rogers, R. R., Ferrare, R. A., Lee, K. P., Kuehn, R. E., and Hostetler, C. A.: The CALIPSO Automated Aerosol Classification and Lidar Ratio Selection Algorithm, J. Atmos. Ocean. Tech., 26, 1994-2014, doi:10.1175/2009jtecha1231.1, 2009.

Pappalardo, G., Amodeo, A., Apituley, A., Comeron, A., Freudenthaler, V., Linné, H., Ansmann, A., Bösenberg, J., D’Amico, G., Mattis, I., Mona, L., Wandinger, U., Amiridis, V., AladosArboledas, L., Nicolae, D., and Wiegner, M.: EARLINET: towards an advanced sustainable European aerosol lidar network, Atmos. Meas. Tech., 7, 2389-2409, 10, 
http://www.atmos-meas-tech.net/7/2389/10/.5194/amt-7-23892014, 2014.

Rogers, R. R., Hair, J. W., Hostetler, C. A., Ferrare, R. A., Obland, M. D., Cook, A. L., Harper, D. B., Burton, S. P., Shinozuka, Y., McNaughton, C. S., Clarke, A. D., Redemann, J., Russell, P. B., Livingston, J. M., and Kleinman, L. I.: NASA LaRC airborne high spectral resolution lidar aerosol measurements during MILAGRO: observations and validation, Atmos. Chem. Phys., 9, 4811-4826, doi:10.5194/acp-9-4811-2009, 2009.

Rogers, R. R., Hostetler, C. A., Hair, J. W., Ferrare, R. A., Liu, Z., Obland, M. D., Harper, D. B., Cook, A. L., Powell, K. A., Vaughan, M. A., and Winker, D. M.: Assessment of the CALIPSO Lidar $532 \mathrm{~nm}$ attenuated backscatter calibration using the NASA LaRC airborne High Spectral Resolution Lidar, Atmos. Chem. Phys., 11, 1295-1311, doi:10.5194/acp-11-12952011, 2011.

Rogers, R. R., Vaughan, M. A., Hostetler, C. A., Burton, S. P., Ferrare, R. A., Young, S. A., Hair, J. W., Obland, M. D., Harper, D. B., Cook, A. L., and Winker, D. M.: Looking through the haze: evaluating the CALIPSO level 2 aerosol optical depth using airborne high spectral resolution lidar data, Atmos. Meas. Tech., 7, 4317-4340, doi:10.5194/amt-7-4317-2014, 2014.

Sakai, T., Nagai, T., Zaizen, Y., and Mano, Y.: Backscattering linear depolarization ratio measurements of mineral, sea-salt, and ammonium sulfate particles simulated in a laboratory chamber, Appl. Opt., 49, 4441-4449, 2010.

Sasano, Y. and Browell, E. V.: Light-Scattering Characteristics of Various Aerosol Types Derived from Multiple Wavelength Lidar Observations, Appl. Optics, 28, 1670-1679, 1989.

Sassen, K. and Khvorostyanov, V. I.: Cloud effects from boreal forest fire smoke: Evidence for ice nucleation from polarization lidar data and cloud model simulations, Environ. Res. Lett., 3, 025006, doi:10.1088/1748-9326/3/2/025006, 2008.

Scarino, A. J., Obland, M. D., Fast, J. D., Burton, S. P., Ferrare, R. A., Hostetler, C. A., Berg, L. K., Lefer, B., Haman, C., Hair, J. W., Rogers, R. R., Butler, C., Cook, A. L., and Harper, D. B.: Comparison of mixed layer heights from airborne high spectral resolution lidar, ground-based measurements, and the WRFChem model during CalNex and CARES, Atmos. Chem. Phys., 14, 5547-5560, doi:10.5194/acp-14-5547-2014, 2014.

She, C.-Y.: Spectral Structure of Laser Light Scattering Revisited: Bandwidths of Nonresonant Scattering Lidars, Appl. Opt., 40, 4875-4884, 2001.

Shipley, S. T., Tracy, D. H., Eloranta, E. W., Trauger, J. T., Sroga, J. T., Roesler, F. L., and Weinman, J. A.: High Spectral Resolution Lidar to Measure Optical-Scattering Properties of Atmospheric Aerosols .1. Theory and Instrumentation, Appl. Optics, 22, 3716-3724, 1983.

Sorensen, C.: Light scattering by fractal aggregates: a review, Aerosol Sci. Tech., 35, 648-687, 2001.

Su, W. Y., Schuster, G. L., Loeb, N. G., Rogers, R. R., Ferrare, R. A., Hostetler, C. A., Hair, J. W., and Obland, M. D.: Aerosol and cloud interaction observed from high spectral resolution lidar data, J. Geophys. Res.-Atmos., 113, D24202, doi:10.1029/2008jd010588, 2008.
Sugimoto, N., Uno, I., Nishikawa, M., Shimizu, A., Matsui, I., Dong, X., Chen, Y., and Quan, H.: Record heavy Asian dust in Beijing in 2002: Observations and model analysis of recent events, Geophys. Res. Lett., 30, 1640, doi:10.1029/2002g1016349, 2003.

Sugimoto, N. and Lee, C. H.: Characteristics of dust aerosols inferred from lidar depolarization measurements at two wavelengths, Appl. Optics, 45, 7468-7474, 2006.

Sugimoto, N., Shimizu, A., Matsui, I., Uno, I., Arao, K., Dong, X., Zhao, S., Zhou, J., and Lee, C.-H.: Study of Asian dust phenomena in 2001-2003 using a network of continuously operated polarization lidars, Water, Air, \& Soil Pollution: Focus, 5, 145-157, doi:10.1007/s11267-005-0732-1, 2005.

Sugimoto, N., Tatarov, B., Shimizu, A., Matsui, I., and Nishizawa, T.: Optical Characteristics of Forest-Fire Smoke Observed with Two-Wavelength Mie-Scattering Lidars and a HighSpectral-Resolution Lidar over Japan, SOLA, 6, 93-96, doi:10.2151/sola.2010-024, 2010.

Tesche, M., Ansmann, A., Müller, D., Althausen, D., Engelmann, R., Freudenthaler, V., and Groß, S.: Vertically resolved separation of dust and smoke over Cape Verde using multiwavelength Raman and polarization lidars during Saharan Mineral Dust Experiment 2008, J. Geophys. Res., 114, D13202, doi:10.1029/2009jd011862, 2009a.

Tesche, M., Ansmann, A., Müller, D., Althausen, D., Mattis, I., Heese, B., Freudenthaler, V., Wiegner, M., Esselborn, M., Pisani, G., and Knippertz, P.: Vertical profiling of Saharan dust with Raman lidars and airborne HSRL in southern Morocco during SAMUM, Tellus Ser. B-Chem. Phys. Meteorol., 61, 144-164, doi:10.1111/j.1600-0889.2008.00390.x, 2009b.

Tesche, M., Müller, D., Gross, S., Ansmann, A., Althausen, D., Freudenthaler, V., Weinzierl, B., Veira, A., and Petzold, A.: Optical and microphysical properties of smoke over Cape Verde inferred from multiwavelength lidar measurements, Tellus B, 63, 677-694, doi:10.1111/j.1600-0889.2011.00549.x, 2011.

Wiegner, M., Gasteiger, J., Kandler, K., Weinzierl, B., Rasp, K., Esselborn, M., Freudenthaler, V., Heese, B., Toledano, C., Tesche, M., and Althausen, D.: Numerical simulations of optical properties of Saharan dust aerosols with emphasis on lidar applications, Tellus Ser. B-Chem. Phys. Meteorol., 61, 180-194, doi:10.1111/j.1600-0889.2008.00381.x, 2009.

Winker, D. M., Hunt, W. H., and McGill, M. J.: Initial performance assessment of CALIOP, Geophys. Res. Lett., 34, L19803, doi:10.1029/2007g1030135, 2007.

Yang, W., Marshak, A., Kostinski, A. B., and Várnai, T.: Shape-induced gravitational sorting of Saharan dust during transatlantic voyage: Evidence from CALIOP lidar depolarization measurements, Geophys. Res. Lett., 40, 3281-3286, doi:10.1002/grl.50603, 2013. 